\title{
Review Article \\ The Challenges Confronting Public Hospitals in India, Their Origins, and Possible Solutions
}

\author{
Vikas Bajpai \\ Centre for Social Medicine and Community Health, Jawaharlal Nehru University, New Delhi, India \\ Correspondence should be addressed to Vikas Bajpai; drvikasbajpai@gmail.com
}

Received 11 January 2014; Revised 17 May 2014; Accepted 19 May 2014; Published 13 July 2014

Academic Editor: Gudlavalleti Venkata Murthy

Copyright (C) 2014 Vikas Bajpai. This is an open access article distributed under the Creative Commons Attribution License, which permits unrestricted use, distribution, and reproduction in any medium, provided the original work is properly cited.

Despite the implementation of National Rural Health Mission over a period of nine years since 2005, the public health system in the country continues to face formidable challenges. In the context of plans for rolling out "Universal Health Care" in the country, this paper analyzes the social, economic, and political origins of the major challenges facing public hospitals in India. The view taken therein holds the class nature of the ruling classes in the country and the development paradigm pursued by them as being at the root of the present problems being faced by public hospitals. The suggested solutions are in tune with these realities.

\section{Introduction}

Some authors have described the big modern day hospitals as "monuments to disease." Indeed, this is what they will be so long as they function as institutions only for curative care, detached from the larger social, economic, cultural, and political context of the people's lives which largely determines their health. Unfortunately, even this curative care has become unaffordable to many common people due to the policy framework governing health sector in the country.

The fact is that public hospitals have become increasingly detached from the larger context in which medicine operates. If the public hospitals are to be made responsive to the health needs of the people, then problems facing these institutions ought to be located in the broader conditions (we may call these structural problems) that influence their functioning, rather than locating these in their inner working alone. This also implies that the solutions to these problems ought to be socially oriented rather than being guided by narrow managerial or technocentric approaches.

Public sector healthcare shall continue having its relevance for a long time in order to reach out healthcare to vast sections of underserved populations in developing countries like India. In the context that the 12th Five-Year Plan Document has rolled out an ambitious scheme to achieve
"Universal Health Care" in the country, this review sets out the following objectives before itself:

(i) elucidate the more important challenges facing public hospitals in India and document their enormity;

(ii) understand the social, economic, and political sources/ factors leading to the emergence of these challenges;

(iii) in accordance with the aforementioned analysis, propose solutions that are feasible within the present political and economic system.

For the purpose of this paper, a public hospital shall include the most peripheral PHC (primary health center) to a tertiary care hospital located in a big city. Even though there are differences in the specific functions of these institutions, they constitute a continuum of care, both preventive and curative. While the lower levels ought to provide more direct preventive and curative services for most of the common diseases, the higher level institutions are supposed to cater to a more selected set of patients who are in need for more specialized services not available at the lower public health facilities. Apart from this, the higher public health facilities have an obligation on providing supervision, training, and technical support to facilitate smoother functioning of the primary level facilities. It follows then that there is a synthesis 
across different levels of public hospitals and breakdown at any level has consequences for all levels.

\section{Structure and Methodology}

After setting out what the author believes to be the main challenges facing public hospitals in India, different secondary sources of information were relied upon to authenticate these challenges. Apart from this, reliance has also been placed on the observations made by the author during his monitoring visits to various health facilities, primarily in the states of Uttarakhand and Uttar Pradesh, while working as a consultant with the National Health Systems Resource Center, a technical advisory body of the Government of India under the Ministry of Health and Family Welfare.

Having thus delineated the major challenges, relying on evidence from relevant literature, different social, economic, and political sources of these challenges have been profiled. The suggested solutions for rectifying some of these social, economic, and political sources have been formulated as per the analysis made in the review and as per the author's understanding. However, it is admitted that the suggested solutions are in deference to the present system's ability to allow changes in the given social, economic, and political structure of the society.

Further, an attempt to comprehensively review the challenges facing a public hospital does not afford the advantage of ostensible clarity that comes with taking up a single focus for study. Alternatively, a compartmentalized approach tends to lose sight of the essentially interrelated nature of different challenges that confront a public hospital in India today. It is our considered opinion that there cannot be a solution that is strictly limited in its scope to a particular aspect of the problem under consideration, without impinging on other aspects. Hence, this is a comprehensive review.

\section{Main Challenges Confronting a Public Hospital}

In our opinion, the main challenges confronting the public hospitals today are as follows:

(1) deficient infrastructure,

(2) deficient manpower,

(3) unmanageable patient load,

(4) equivocal quality of services,

(5) high out of pocket expenditure.

3.1. Deficient Infrastructure. The format of the public health structure in the country draws directly from the recommendations of the Bhore Committee Report, 1946. However, the public health infrastructure has evolved lags far behind in matching the content and the spirit of the committee's report. The committee proposed the implementation of its recommendations in two distinct phases- "three-million plan" and the "ten-year plan."

The "three-million plan" laid down the required health infrastructure to provide for the health needs of an average district in India having a population of three million. This was to be implemented over a period of three to four decades. Anticipating resource constraints, both in terms of manpower and money to make such an infrastructure available in a short time, the committee recommended a shorter "ten-year plan" to be implemented first. Table 1 gives a comparison between the "ten-year plan," the "three-million plan," and the public health infrastructure available at present in the country.

As against the 0.24 beds per 1000 population that were available in British India, the committee's overall plan for development of health services in India provided for achieving 1.03 beds per 1000 population within ten years of implementation of the plan and a ratio of 5.67 beds $/ 1000$ population in thirty to forty years. The committee further stated that:

"We consider moreover, that our recommendations constitute an irreducible minimum, and were it not for the limitation imposed by the inadequacy of staff and funds; we should unhesitatingly have proposed a more comprehensive scheme than the one indicated." [1, Page 31].

However, even a cursory look at Table 1 shows that what was considered as "irreducible minimum" by the committee proved to be a formidable task to achieve for the health planners of the country.

The UPA (United Progressive Alliance) Government launched the ambitious "National Rural Health Mission" (NRHM) in 2005 to bolster the rural health infrastructure. After completion of the first phase in 2012 the mission is now in the second phase of its implementation. To begin with, the mission was meant to bring the EAG (Empowered Action Group) states which lagged far behind the rest of the country in health infrastructure, at par with the rest of the country. Table 2 provides the rural infrastructure status in the EAG states (Jammu and Kashmir and Himachal Pradesh excluded) as of March 2012.

It is clearly evident from the table that the average shortfall for different types of facilities is between two to three times more in EAG states as compared to the nonEAG states. Similarly, the average population served per facility continues to remain much higher for EAG states as compared to non-EAG states. With the notable exceptions of Chhattisgarh, Odisha, Uttarakhand, and Jharkhand for the number of CHCs in position, the shortfall for different levels of facilities in the other five states is much higher than the all India average.

The relative advantage of states like Chhattisgarh, Odisha, and Uttarakhand may well be illusionary because, as we will see shortly, mere availability of infrastructure does not mean it is delivering the required services, which, along with infrastructure, also depend on availability of amenities like water, electricity, beds, medical and paramedical manpower, and spatial distribution of available infrastructure. Table 3 illustrates some of the other deficiencies of the available infrastructure which undermines its functional status.

Nonavailability of facilities like water and electricity can only be expected to deeply undermine the functioning of 


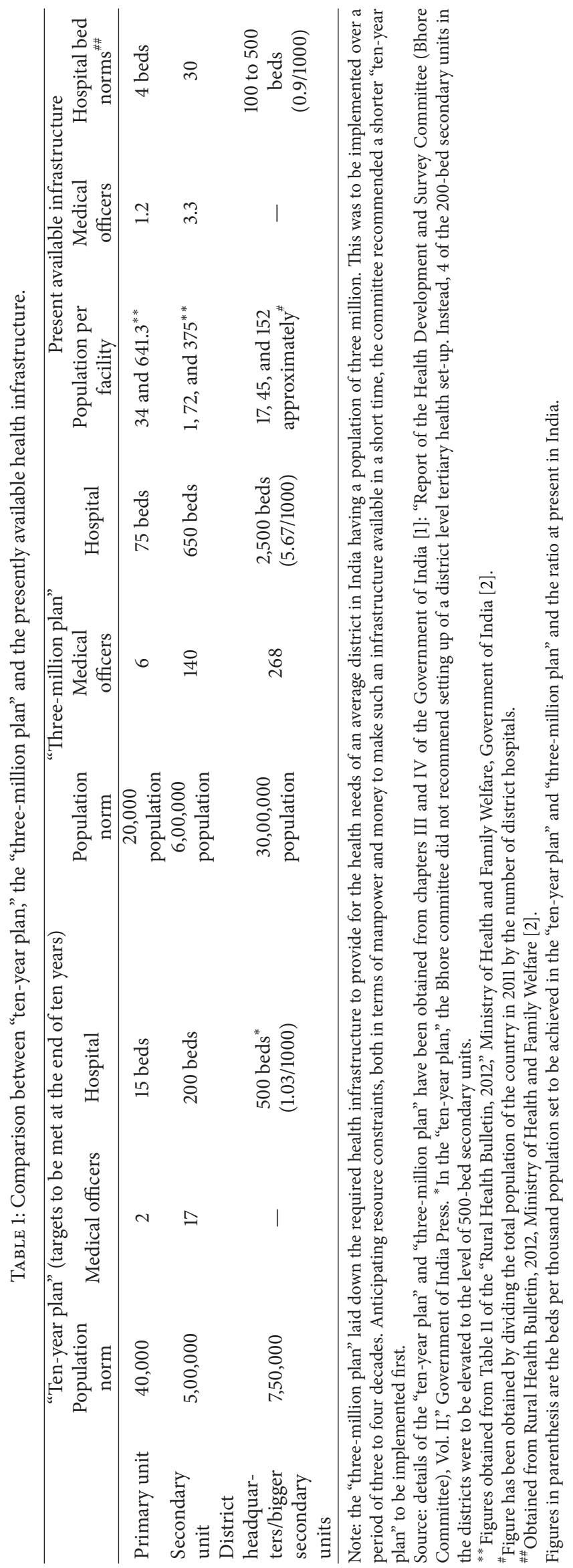




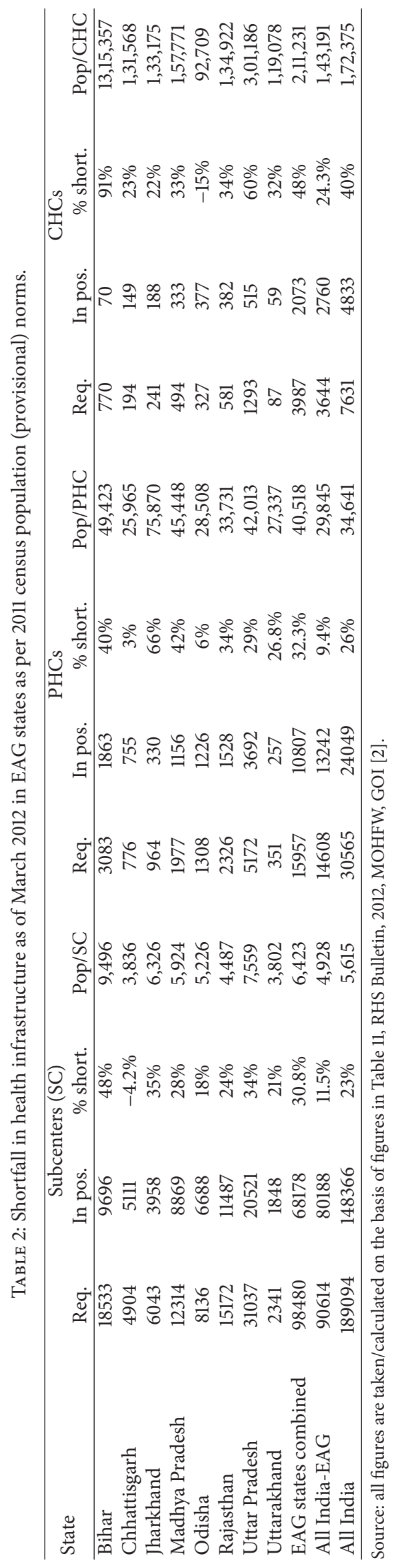


TABLE 3: Some of the deficiencies in the available infrastructure.

\begin{tabular}{lc}
\hline Indicator & Shortfall \\
\hline \% of subcenters without ANM & $3.2 \%$ \\
\% of PHCs without doctor & $3.8 \%$ \\
\% subcenters without regular water supply & $25.5 \%$ \\
\% subcenters without electric supply & $25.5 \%$ \\
\% subcenters without all whether motor able roads & $6.6 \%$ \\
\% of PHCs without regular electric supply & $8 \%$ \\
\% PHCs without regular water supply & $10.7 \%$ \\
\% PHCs without all-weather motor able roads & $5.8 \%$ \\
\hline
\end{tabular}

Source: RHS Bulletin, 2012, MOHFW [2].

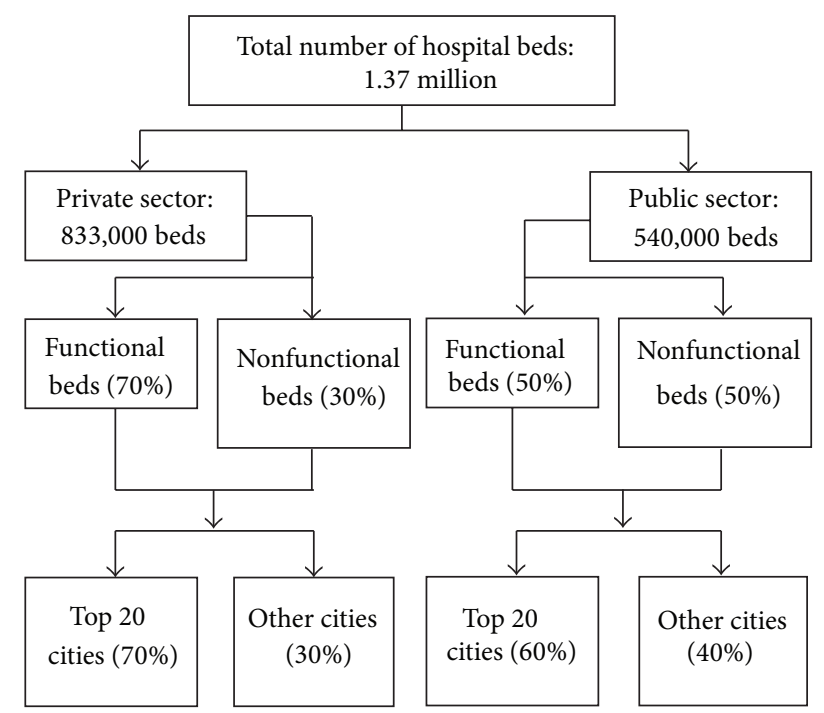

FIGURE 1: Distribution of available hospital beds in India. Source: [8].

existing facilities. It is very much possible that if the facility has one resource, it may not have other resources to optimally utilize the available resources; for example, if a health worker is available at the facility, it may not have water/electricity, thus undermining the ability of the health worker to perform his/her functions optimally.

Mismatch in the spatial distribution of infrastructure is another factor that magnifies the deficiency of infrastructure. Figure 1 illustrates this aspect very well. One can clearly see that there is a concentration of available beds in a tiny proportion of bigger cities. If the same beds were to be more equitably distributed between cities and between urban and rural areas, availability of the same infrastructure would have gone a longer way in ameliorating the curative needs of the people. However, this state of affairs is a logical outcome of the development paradigm pursued in the country rather than an inadvertent occurrence.

A comparison of availability of hospital beds per 1000 population between India and some of the much poorer countries (Table 4) offers a hitting comment on the sufficiency of country's health infrastructure. Many of the subSaharan countries and a country as impoverished as TimorLeste seem to be doing much better.
3.2. Deficient Manpower. Deficiency of human resources in health adds further insult to injury caused by deficiency of health infrastructure. Deficiency of human resources in health occurs at several levels-between regions, between rural and urban areas, and between the public and private sectors. On the one hand, there is unwillingness of doctors and other health personnel to serve in rural areas; on the other hand, even in the urban areas, there is a preponderance of the health manpower in the dominant for profit private health sector in the country, thereby putting their services beyond the reach of the majority of poor in the country.

The deficiency of specialists in rural healthcare is as high as more than 90 percent in Chhattisgarh, Jharkhand, and Rajasthan, while being at nearly 86 percent in Uttarakhand, and Odisha. The interregional disparities are also explicit with there being a wide gap in the deficiency of both the specialist and graduate doctors between the EAG and the non-EAG states. Even though there seems to be an excess of GDMOs in Bihar and a relatively less shortfall in Jharkhand as against the required posts, this is highly misleading as the overall physicians per 10,000 population ratio remain dismal at .5 for both the states. The "required" here signifies required as against the sanctioned posts and not requirement as per some population norm. For example, the total rural population of Bihar was 92.07 million as per 2011 census, whereas the total number of required doctors (specialists and GDMOs) in rural health set-up as per Table 5 is only 2773. This would amount to only .3 doctors per 10,000 rural populations which by no standard is desirable. Even after seven years of implementation of NRHM (National Rural Health Mission), there remains a wide gap in the availability of allopathic doctors in the rural areas between the non-EAG states and EAG states. In the former, it is 2.25 times more.

Despite deficiencies in their training as managerial physicians, doctors have generally come to be perceived as responsible members of health care team comprising paramedical and other supportive staff. They are expected to lead the way in problem solving and supervising the work of other team members. As such, deficiency of doctors, besides impacting the delivery of curative services, may also reflect adversely in the overall functioning of the health team.

Deficiency of health personnel is by no chance limited to doctors alone. Figure 2 illustrates the shortfall in various categories of paramedical personnel in the public sector rural healthcare system. It may be pointed here that some of the countries such as Soviet Union in the immediate aftermath of Bolshevik revolution and China made up for the deficiency in strength of doctors by training and deploying a huge cadre of paramedical public health personnel in the poorly served areas.

Shortage of manpower is only made worse by the absence of a comprehensive and integrated health manpower policy dealing with health manpower requirement projection, manpower production, training, recruitment, career development, supportive supervision, skill enhancement, postings in underserved areas, retention and transfers, and so forth $[16,17]$. This remains the state of affairs in spite of a number of official committees having stressed the need for such a policy 
TABLE 4: A comparison of the availability of hospital beds for selected countries.

\begin{tabular}{lcccccccc}
\hline Country & Timor-Leste & Gabon & Equatorial Guinea & Djibouti & Kenya & Botswana & Zambia & India \\
\hline Beds/1000 population & 5.9 & 6.3 & 2.1 & 1.4 & 1.4 & 1.8 & 2 & 0.9 \\
\hline
\end{tabular}

Source: World Development Indicators, World Bank DataBank [3].

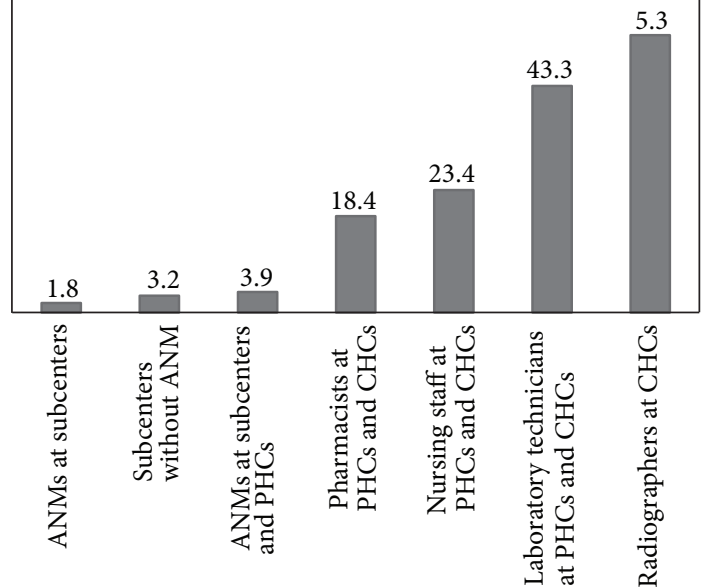

FIGURE 2: Shortfall in various categories of paramedical staff in rural healthcare set-up, all India. Source: based on figures in RHS Bulletin, $2012[2]$.

beginning with the Bhore Committee Report of 1946 itself [18].

The skewed distribution of the available health cadre of different categories which has left the rural, tribal, and hilly areas grossly underserved is a direct consequence of deficiency of human resources and a lack of integrated health manpower resource development policy. The density of doctors is four times and that of nurses is three times higher in urban areas as compared to the rural areas [19]. According to $\mathrm{WHO}$, of the 57 countries facing human resources in health crisis, India's ranking is 52nd [20].

Statistics by themselves may still not bring forth the acuteness of the challenges as perhaps the description of the ground realities can. While working as a consultant at the National Health Services Resource Center (NHSRC), the author had the opportunity to visit many health facilities in different districts of Uttar Pradesh and Uttarakhand. The following are observations from some of the visits.

(i) During a monitoring visit in June 2013 by the author to the district hospital in Pithoragarh district of Uttarakhand state, it was found that the doctors and the employees of the hospital were on strike in protest against roughing up of some hospital staff by the relatives of an 18- or 19-year-old boy who died the previous night of some complication following the operation for abdominal/inguinal hernia (a simple and routine surgery provided that there is no strangulation of the intestines at the hernia site).

At the time the boy died, there were only two nurses, one in the casualty of the hospital and the other to take care of admitted patients, in various wards, in a 120bed hospital. After the regular working hours there is only one doctor available for all these patients, which is too in the emergency. So in the absence of doctors and nurses in the wards after routine hours, it is for the attendants to be able to locate them in the hospital in case their patient requires medical attention, provided of course that the attendants are able to judge the criticality of their patient's discomfort.

(ii) Likewise, in the 100-bed district women hospital at Jhansi, after four p.m., there is only one nurse (who was working on contract basis at the time of the author's visit) to take care of the labor room, the ward, and an occasional cesarean section that may take place. 100 beds do not mean only 100 patients, because one needs to count the babies of the delivered mothers as well, who require even greater medical attention.

(iii) The conditions at the 100 bed "Mahatma Gandhi Smarak District Hospital" at Naugarh, the district headquarter of Siddharthnagar district in UP, are even worse. The patients are pretty much on their own after 4 p.m. as the only available nurse is kept busy in the labor room, while the doctor mans the emergency. The hospital had just 5 nurses on its rolls at the time of writing to provide all the nursing care required at the hospital.

(iv) Almost similar conditions were to be found at district general and the district women hospital in Faizabad district of Uttar Pradesh. According to the information provided by the hospital authorities in February 2013, there had been 26 maternal deaths at the hospital in the last one year out of a total of 5860 deliveries that took place at the hospital. This works out to a maternal mortality rate of a whopping 443.7 per 100,000 live births.

(v) There was just one obstetrician and gynecologist in both Pithoragarh and Siddharthnagar districts to cater to cases requiring cesarean deliveries. The specialist in Pithoragarh was putting up around $580 \mathrm{~km}$ away from her family in Gwalior, situated in Madhya Pradesh state. She was forthright, "had I been posted in plain areas I could have at least visited my family easily; I am only biding my time and shall leave the moment I get a more suitable job."

Irrespective of the high tech nature of modern healthcare delivery, it is the personnel, who wield the technology to provide services, who matter the most. The impact of deficiency or absence of one category of health personnel is not restricted to "a particular service" delivery but impacts 


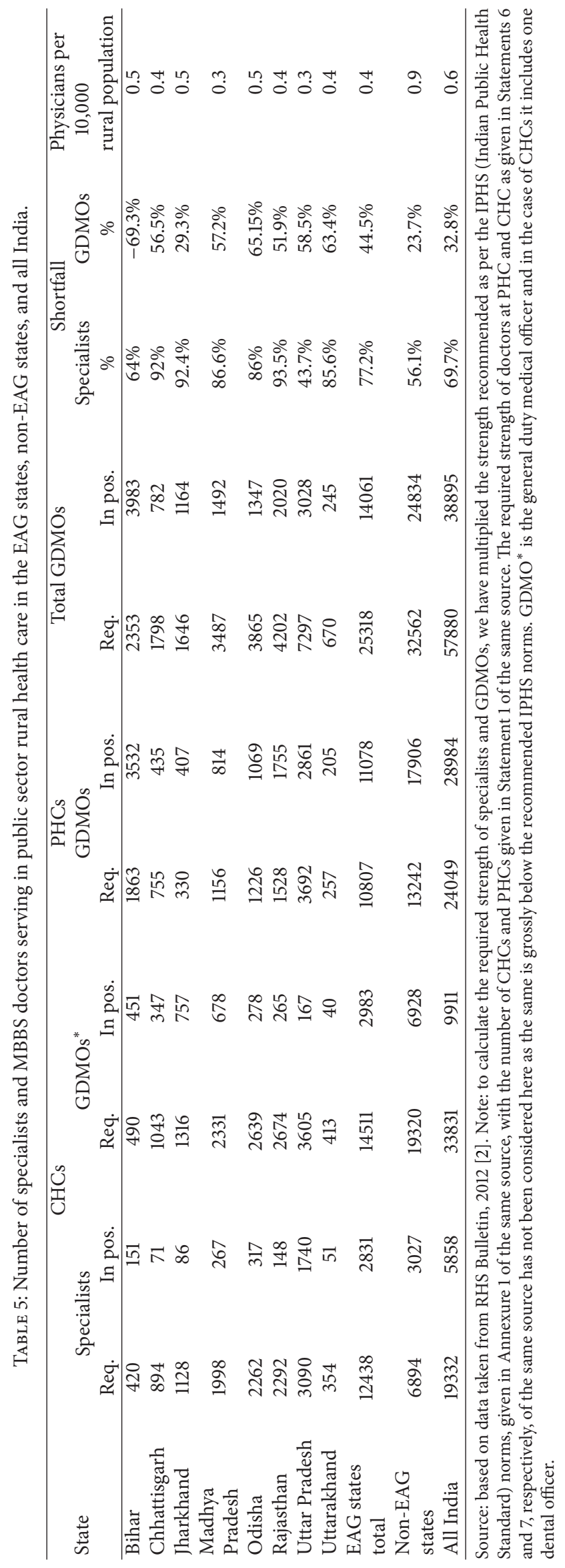


TABle 6: Deficiencies in functioning of PHCs and CHCs in India.

Primary health centers

PHCs without residential quarter for medical officer

Community health centers

CHCs not performing even normal delivery services

Source: GOI, 2010 [4]. Note: these statistics are of a time of the beginning of NRHM; there may have been marginal improvement over the period of implementation of NRHM but comparable national level statistics for a later period are not available. Anyhow, it is nobody's claim that the implementation of NRHM has reduced the workload on public health facilities in bigger urban centers, especially, as almost the entire focus of NRHM has been on improving the maternal and child health services and in that also on improving the rates of institutional deliveries with the objective of reducing the maternal and infant mortality. Unfortunately, even the delivery of these services remains far from desirable and of equivocal quality.

the integrated nature of functioning of a modern hospital. Moreover, deficiency of personnel means overburdening of the personnel who are present and who have to work under intense pressure of various kinds. This cannot but have a negative impact on the morale of the health workers. The medical officer in charge of the $\mathrm{CHC}$ at Baijnath in district Bageshwar, Uttarakhand, lamented that: "given the patient load and strength of doctors at my facility I am hardly able to give a minute per patient in the OPD; this makes me wonder what the worth of my work is; what quality of services are we providing?”

3.3. Unmanageable Patient Load. Secondary or tertiary level public hospital in bigger cities is today bursting at seams due to a heavy rush of patients. The huge unplanned increase of Indian cities has resulted in urbanization of rural poverty causing expansion of slums and marginal populations starved of health and other basic amenities. Deficiency of urban health infrastructure, overcrowding in hospitals, lack of outreach, and functional referral system, standards, and norms for urban health care delivery system, social exclusion, unavailability or ignorance of information for accessing modern health care facilities, and lack of purchasing power are some of the issues that have been identified as challenges to urban healthcare in the country [21]. These factors are further complicated by poorly functioning subcenters, PHCs, and $\mathrm{CHCs}$ resulting in people from rural areas having to increasingly depend on hospitals in the bigger cities and towns for their curative needs thereby stretching the infrastructure at these hospitals to limits. Some idea of the level of functioning of peripheral health facilities in India can be had from Table 6.

Problems reflected in Table 6 are further accentuated by high rates of absenteeism among health workers. According to a nationally representative survey conducted in 2003, nearly 40 percent of the doctors and other health service providers were found to be absent from their posts on a typical working day. While absenteeism among doctors varied between 30 percent in Madhya Pradesh and 67 percent in Bihar (the figure on availability of GDMOs, given in Table 5, in excess of requirement out to be viewed in this context); it was found to be $30 \%$ among pharmacists and laboratory technicians [22].

The pattern of organization of the health services into primary, secondary, and tertiary levels implies a referral system between these levels such that the patients who cannot be handled at the primary or secondary levels can be referred to the higher levels for appropriate management. Referral system, however, does not imply exclusivity between different levels of health care. Rather it entails an active cooperation between them which is necessary for the development of the health services system as a whole. In this respect, the Bhore Committee Report states the following.

"The heads of different sections in the district hospitals dealing with medicine, surgery and so on ... it will be of advantage if they can occasionally visit the secondary unit hospitals and a certain number of primary unit hospitals and inspect and guide the professional work of officers discharging corresponding duties in these hospitals. Such contacts should help to improve the standard of professional work carried out in the hospitals of the districts generally" [1, Page 21].

Apart from this, the committee also laid stress on the need for the tertiary level hospitals to play a role in the training and continuing skill enhancement for different categories of health personnel [23, Page 22].

Contrary to this there is hardly a "referral system" worth its name that operates in the public health set-up of the country. Rather the poor functioning or even the absence of the peripheral health services in large parts leaves no alternative before the people but to throng to the already overstretched facilities of bigger hospitals in towns and cities, bringing about a marked deterioration in their functioning.

A study conducted at three referral hospitals in Lucknow district showed that nearly 90 percent of the patients coming 
to these hospitals were new patients and, of these, two thirds had reached directly without any referral. Overall, only around a tenth of all patients attending these hospitals had been referred by someone, while the rest were all self-referred [24].

This trend is further worsened by some of the policy prescriptions of the government. For example, during a field visit to one of the "empowered group states" of north India by the author, the principal secretary health of the state in a meeting acknowledged the immense pressure on the largest public hospital in the capital of the state on account of the "Janani Suraksha Yojana," an institutional delivery scheme, under NRHM (National Rural Health Mission), sponsored by the central government to reduce the maternal mortality and the neonatal mortality rates. Because of the nonfunctioning or under performance of the peripheral health institutions as delivery points and the assistance of a government sponsored ambulance service, there had been such a rush of maternity cases to the hospital that the doctors pleaded: "for God's sake stop this madness." Another fall out of this scenario has been that the ambulance service sponsored by the state has established a world record in "deliveries conducted on way" to the hospital [25].

While decline in the maternal and infant mortality rates due to this scheme is circumspect, it has surely stretched the services of the state's tertiary healthcare services beyond capacity.

3.4. Equivocal Quality of Services. Patient load much in excess of what the infrastructure is capable of handling is bound to undermine the quality of care. "Chacha Nehru Bal Chikitsalaya," a Delhi government run child care hospital in east Delhi had much to celebrate when it became the first public hospital in the capital to be accredited by the National Accreditation Board for Hospitals (NABH). However, with the patient load bursting at its seams, the hospital soon found itself struggling to survive. Till date it has been difficult to arrange sufficient resources for the much required expansion of infrastructure to cope with the rush of patients [26].

Apart from general deficiencies in the development of public health infrastructure in the country, there has been a particularly marked deterioration in services of public hospitals in more than two decades of pursuit of neoliberal policies in general and in health sectors as well which have been oriented towards the strengthening of private health care. The growing dominance of private healthcare has resulted in the molding of public hospitals also in the image of the private hospitals. Some of the steps in this direction have been outsourcing of many services in public hospitals such as security, laundry, cleaning, kitchen services, and, in later stages, even the diagnostic and curative facilities on public-private partnership mode. Progressive imposition of user charges is another of such features [27].

While there is no evidence of these measures having resulted in improvement of the services of public hospitals, there is every reason to believe that these measures have made the services of public hospitals more inaccessible to the common man. Despite the persistent rush of patients. Figure 3 shows that the proportionate share of public hospitals in

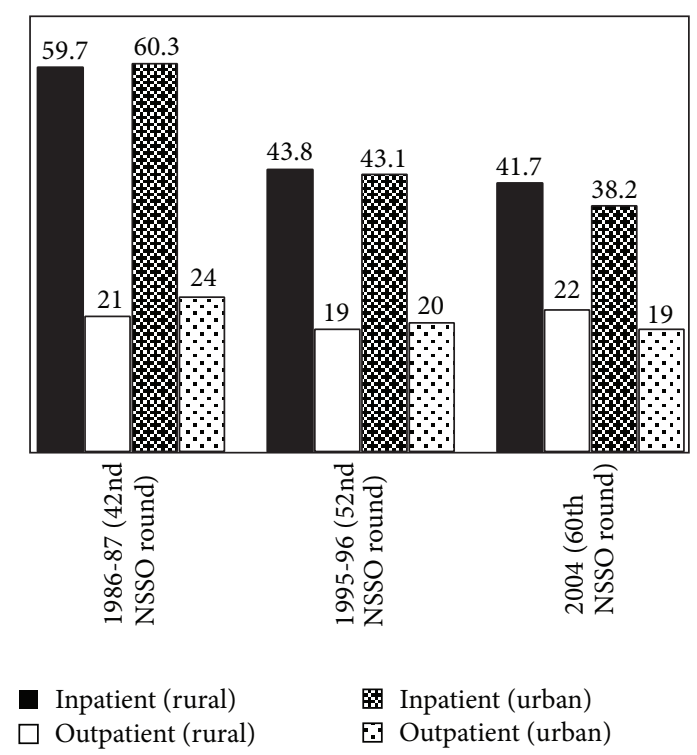

FIGURE 3: Inpatient and outpatient share of public hospitals in rural and urban areas. Source: [6].

hospitalized care has continued to decrease while it is about stagnant for outpatient care. Apart from this, the private sector has been poaching on the trained manpower of public hospitals to its expertise $[28,29]$ which cannot but be at a cost to the quality of services in public hospitals.

3.5. High Out of Pocket Expenditure. The last "National Health Accounts" for India published in 2004-05 unambiguously stated: "Among all the sources, households contributed a significant portion at $71.13 \%$ of total health expenditure for availing health care services from different health care institutions. This covers expenditure on inpatient, outpatient care, family planning, and immunization, and so forth" [30]. Table 7 gives some health spending patterns for selected group of countries, India and for India's neighboring countries. The only saving grace for India is that, among its neighbors, Pakistan and Myanmar spend lesser public resources on health than India. India's public health expenditure fails to match even that of the least developed countries and subSaharan Africa.

It is well acknowledged that catastrophic health expenditure is a significant cause for people being pushed below poverty line in India. Table 8 shows that 2.13 percent more people were pushed below poverty line on account of the out of pocket (OOP) expenditure on health between 199394 and 2004-05. The decade between 1993-94 and 2004-05 was the period when neoliberal economic reforms were on their zenith. The reading of the data in Tables $8,9,10$, and 11, therefore, cannot but be with reference to the impact of these reforms on people's health condition.

During this period, there was increase in OOP expenditure as a proportion of the total household $(\mathrm{HH})$ consumption expenditure across expenditure quintiles. Maximum increase was seen in the "richest" quintile.

Table 9 makes it evident that both inpatient and outpatient care is much costlier in private sector. If we see the 
TABLE 7: Health spending indicators for selected group of countries, India and India's neighbors, 2010.

\begin{tabular}{|c|c|c|c|c|}
\hline Country/Group of countries & $\begin{array}{c}\text { Public health } \\
\text { expenditure as } \% \text { of GDP }\end{array}$ & $\begin{array}{l}\text { Private expenditure on } \\
\text { health as \% of total } \\
\text { expenditure on health }\end{array}$ & $\begin{array}{c}\text { Out of pocket } \\
\text { expenditure as \% of } \\
\text { private expenditure on } \\
\text { health }\end{array}$ & $\begin{array}{l}\text { Out of pocket } \\
\text { expenditure as \% of total } \\
\text { expenditure on health }\end{array}$ \\
\hline South Asia & 1.08 & 70.9 & 80.7 & 61.5 \\
\hline India & 1.06 & 71.8 & 86.0 & 61.8 \\
\hline Afghanistan & 2.35 & 77.5 & 94.0 & 72.8 \\
\hline Bangladesh & 1.35 & 63.5 & 96.6 & 61.3 \\
\hline Bhutan & 3.60 & 15.4 & 94.7 & 14.5 \\
\hline China & 2.70 & 45.7 & 77.2 & 35.3 \\
\hline Maldives & 3.80 & 39.2 & 71.6 & 28.1 \\
\hline Myanmar & 0.24 & 87.9 & 92.7 & 81.5 \\
\hline Nepal & 1.89 & 62.6 & 90.4 & 56.6 \\
\hline Pakistan & 0.79 & 71.8 & 88.0 & 63.2 \\
\hline Sri Lanka & 1.57 & 54.4 & 81.9 & 44.6 \\
\hline Cuba & 9.70 & 4.8 & 100 & 4.8 \\
\hline USA & 8.49 & 51.8 & 22.7 & 11.8 \\
\hline OECD countries & 7.94 & 37.4 & - & - \\
\hline Lower middle income countries & 1.51 & 64.6 & 85.8 & 56.4 \\
\hline Low income countries & 2.11 & 62.9 & 75.9 & 49.6 \\
\hline Least developed countries & 2.18 & 60.9 & 80.7 & 50.5 \\
\hline $\begin{array}{l}\text { Sub-Saharan Africa (developing } \\
\text { countries) }\end{array}$ & 2.8 & 56.8 & 62.8 & 30.9 \\
\hline
\end{tabular}

Source: Health Nutrition and Population Statistics in World Bank DataBank. Available at http://databank.worldbank.org/data/views/variableselection/ selectvariables.aspx?source=health-nutrition-and-population-statistics on 15th August 2013.

findings of Tables 8 and 9 in light of Figure 3, it becomes clear that increasing share of private sector in provisioning of healthcare is, to a large extent, responsible for increasing OOP expenditure on health. With the position of public healthcare becoming even more dwarfed, the private sector has increasingly come to set the standards both for the care and its cost at terms congenial to its profits. Increasing commercialization of the services of public hospitals through measures like imposition of user charges at all levels under the impact of dominant private sector has heightened the challenges facing a public hospital in meeting the people's curative needs.

\section{The Social and Political Origins of the Crisis of a Public Hospital}

The present always originates from the womb of the past. In order to understand the origins of the challenges facing a public hospital, we need to put things in their historical perspective. It is instructive here to recall the famous minute of Thomas McCulay on education in India delivered on 2nd February 1835. Addressing the British Parliament, he said:

"We must at present do our best to form a class who may be interpreters between us and the millions whom we govern; a class of persons, Indian in blood and color, but English in taste, in opinions, in morals, and in intellect" [31].
How well the designs of colonial masters have fructified is epitomized by the following words of our present Prime Minister which he said in Oxford on a visit during his first tenure as Prime Minister:

"Today, with the balance and perspective offered by the passage of time and the benefit of hindsight, it is possible for an Indian Prime Minister to assert that India's experience with Britain had its beneficial consequences too. Our notions of the rule of law, of a constitutional government, of a free press, of a professional civil service, of modern universities and research laboratories have all been fashioned in the crucible where an age-old civilization met the dominant Empire of the day. These are all elements which we still value and cherish. Our judiciary, our legal system, our bureaucracy, and our police are all great institutions; derived from British-Indian administration and they have served the country well” [32].

Peoples' long experience of governance over 65 years since independence attests to the truthfulness of these words. There is much that can be said and demonstrated by way of highlighting the essentially reactionary character of India's ruling classes towards the overwhelming mass of impoverished Indians. Not all of that need be gone into here. Our intent is only to bring out this reactionary character since this 


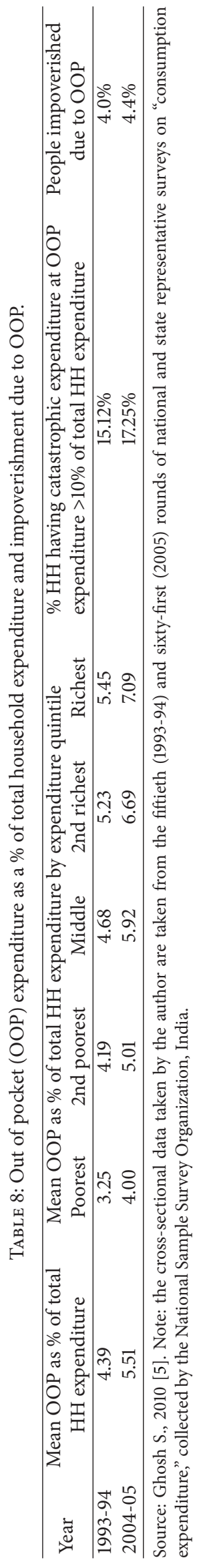


TABLE 9: Average medical expenditure (Rs) per hospitalization and nonhospitalization case.

\begin{tabular}{|c|c|c|c|c|c|c|}
\hline \multirow{3}{*}{$\begin{array}{l}\text { Type of } \\
\text { hospital }\end{array}$} & \multicolumn{4}{|c|}{ Expenditure per hospitalization case (Rs) } & \multicolumn{2}{|c|}{$\begin{array}{l}\text { Expenditure per } \\
\text { nonhospitalization } \\
\text { case (Rs) }\end{array}$} \\
\hline & \multicolumn{2}{|c|}{ Rural } & \multicolumn{2}{|c|}{ Urban } & \multirow{2}{*}{$\begin{array}{l}\text { Rural } \\
2004 \\
\end{array}$} & \multirow{2}{*}{$\begin{array}{c}\text { Urban } \\
2004\end{array}$} \\
\hline & 2004 & 1995-96 & 2004 & 1995-96 & & \\
\hline $\begin{array}{l}\text { Government } \\
\text { hospital }\end{array}$ & 3,238 & 2,080 & 3,877 & 2,195 & 11 & 7 \\
\hline $\begin{array}{l}\text { Private } \\
\text { hospital }\end{array}$ & 7,408 & 4,300 & 11,553 & 5,344 & 246 & 299 \\
\hline Any hospital & 5,695 & 3,202 & 8,851 & 3,921 & - & - \\
\hline
\end{tabular}

Source: GOI, 2006 [6], Statements 28 and 32.

TABLE 10: Availability of allopathic doctors in the rural healthcare set up in India.

\begin{tabular}{|c|c|c|c|c|c|}
\hline Year & $2005^{* *}$ & 2007 & 2008 & 2010 & 2011 \\
\hline Rural population & $78,14,88,000^{*}$ & $79,99,05,000^{*}$ & $80,88,43,000^{*}$ & $82,61,73,000^{*}$ & $83,30,87,662$ \\
\hline $\begin{array}{l}\text { Total government } \\
\text { doctors in rural } \\
\text { health sector (a) }\end{array}$ & 23,858 & 27,725 & 28,654 & 42,584 & 45.062 \\
\hline $\begin{array}{l}\text { Doctors/1000 rural } \\
\text { population }\end{array}$ & 0.03 & 0.03 & 0.04 & 0.05 & 0.05 \\
\hline $\begin{array}{l}\text { Total number of } \\
\text { government } \\
\text { allopathic doctors (b) }\end{array}$ & 67576 & 76542 & 84852 & 85254 & 97648 \\
\hline $\begin{array}{l}\text { Total number of } \\
\text { allopathic doctors } \\
\text { registered with } \\
\text { IMC/SMCs in the } \\
\text { country (c) }\end{array}$ & 660801 & 731439 & 761429 & 846172 & 921877 \\
\hline $\begin{array}{l}\text { Total number of } \\
\text { allopathic doctors in } \\
\text { urban areas }(c-a)\end{array}$ & 636943 & 703714 & 732775 & 803588 & 876815 \\
\hline $\begin{array}{l}\text { Ratio of the rural to } \\
\text { urban allopathic } \\
\text { doctors }(c-a) / a\end{array}$ & $1: 26.7$ & $1: 25.4$ & $1: 25.6$ & $1: 18.9$ & $1: 19.5$ \\
\hline
\end{tabular}

Source: * Figures for rural population for the respective year have been calculated from tables Projected Total Population by Sex in India (As on 1st March, 2001 to 2026) and Projected Urban Population by Sex in India (As on 1st March, 2001 to 2026) available from http://indiastat.com. ${ }^{* *}$ Figures for the year 2005 have been taken from the comparative tables available in Bulletin of Rural Health Services (RHS), 2011 [7]. Figures for the respective years have been taken from the RHS bulletin for the respective year. Note: It need be noted that the availability of doctors in rural health services is the availability as on records. However, there are large variations in the actual availability of doctors in the rural health institutions due to problems like absenteeism, unequal posting of doctors at different institutions. In some of the states, among the allopathic medical graduates posted at rural healthcare institutions, there are a good number of dental graduates who would find it difficult to handle many of the health problems of the people not covered by their discipline.

To calculate the total allopathic doctors (excluding dental surgeons) in urban areas we have presumed that the govt. doctors posted in rural areas are the only allopathic doctors in rural areas, which is largely true with some variations. As regards the availability of allopathic doctors in urban areas, the figures are only approximations because we have presumed that all the doctors registered with the medical councils and who are not serving in rural health services to be working in urban areas, whereas the fact is that a good number of them migrate out of the country.

has had implications for formulation of development policy in the country.

The very fact that Indian ruling classes have retained the colonial coercive machinery in letter and in spirit speaks volumes regarding their sincerity towards ensuring the welfare of India's impoverished masses. The following passage regarding the "Indian Police Act of 1861" brings forth the true meaning of "Our notions of the rule of law" that the Prime Minister spoke of at Oxford.

"The Indian Police Act of 1861 was primarily a mechanism to subjugate the people, and the traditional cooperation of the community was lost sight of in the concerns for law and order. The imperative need was to develop a sense of fear of authority in the entire population, and it was achieved through this system of ruler's police. The police were to be shaped as an instrument of the Raj, one where men were disciplined, armed and without hesitation would follow British officers' orders" [33].

The act per se continues to be in force ipso facto. The only difference is that the place of "British officer" has been taken by the "Brown Sahib." Little wonder then that between 2001 and 2010, 14,231 custodial deaths were recorded by National 
TABLE 11: Top 5 countries for international medical graduates (IMG) physicians working in the United States.

\begin{tabular}{lcc}
\hline Country & $\begin{array}{c}\text { Total IMG } \\
\text { physicians }\end{array}$ & $\begin{array}{c}\text { \% of total IMG } \\
\text { population }\end{array}$ \\
\hline India & 51,447 & 20.7 \\
Philippines & 20,601 & 8.3 \\
Mexico & 13,834 & 5.6 \\
Pakistan & 12,111 & 4.9 \\
Dominican & 7,979 & $3.2 \%$ \\
Republic & & \\
\hline
\end{tabular}

Source: Tables 1 and 2 in AMA, 2010 [9].

Total number of physicians in the USA: 985,375.

Total number of IMG physicians: 254,396 (from 127 countries).

\% IMG physicians in USA: $26.0 \%$.

Human Rights Commission (NHRC); that is, on an average, 4.33 person died in police and judicial custody in India every day [34]. We hope that this example would have carried through the point intended to be made. If not, we would further attempt to bring it home through examples specific to health policy paradigm that has been pursued in the country.

The recommendations of the Bhore Committee (its report was accepted by the government in 1946) constitute the most elaborate, liberal, and, by far, the most desirable of the schemes for the development of health sector in the country till date. And, yet, expressing its concerns regarding the population problem, the committee said:

"A reduction in the rate of growth of population may be brought about by permitting the death rate in the community to rise. Our social instincts militate against this ... One of the objectives universally accepted in all civilized countries is the reduction of morbidity and mortality in the community. We have, therefore, to turn to other means of decreasing the rate of growth of population" [1, Pages 483-484].

It seems, but for the norms imposed by the civilized countries, that it might as well have recommended "letting the death rate to rise" as a means of controlling population growth. Their contempt for the people, nonetheless, is rather forthright. The committee states further:

"A birth control campaign has certain inherent dangers ... Contraceptive practices are, therefore, more likely to be used by the more successful and intelligent sections of the community than by those who are improvident and mentally weak. It may also be mentioned that a certain number of defects, and diseases are known to be inheritable... The classes (emphasis ours) which processes many of these undesirable characteristics are known to be generally improvident and prolific (emphasis ours). A continued high birth rate among these classes, if accompanied by a marked fall in the rate of growth of the more energetic, intelligent and ambitious sections of the population, which make much the largest contribution to the prosperity of the country, may be fraught with serious consequences to national welfare" [1, Page 487].

There need be no confusion as to which class is being despised-precisely, the one which depends most on the services of public sector healthcare. There is a continuum, between 1946 and today, in the contempt that the rulers reserve for the commonest of the common Indians. In 2009, our present honorable minister for health and family welfare at the centre had commented:

"If there is electricity in every village, then people will watch TV till late at night and then fall asleep. They won't get a chance to produce children ... When there is no electricity there is nothing else to do but produce babies" [35].

4.1. Class Character of the Ruling Elite and the Development of Health Services in India. Unlike the bourgeoisie democracies of the West, the democratic form of government in India did not evolve as a result of a thorough going struggle encompassing commonest of the common Indians in struggle for their liberation. The bourgeoisie democratic "format" of polity in India was imposed by the colonial rulers from above and adopted as such by the native "McCulaian" elite. So while the better off among different sections of the society are coopted in the ruling structure, the vast base of the society remains undemocratic with there being little scope for the subaltern sections to assert themselves except within the limits defined by and the ways prescribed by the ruling classes.

True to their comprador class character, the rulers in India developed the healthcare system in the image of these systems as prevalent in the developed capitalist countries rather than develop a "healthcare system" that was sensitive to the local needs and relied on the resources available in the country.

India and China set out to meet their "tryst with destiny" as modern states almost at the same time, with China in fact being two years late in this regard, 1949 as against 1947 for India. Both were ancient civilizations and repositories of some of the most long standing indigenous systems of medicine that were rooted in popular culture and enjoyed widespread credibility among the people. The size of their populations, poverty, very low levels of development, widespread hunger, and disease were other features common to both. And yet the trajectories that health systems development took in either country were remarkably divergent.

China relied on a mix of modern medical knowledge and the indigenous knowledge systems to turn around the health of its predominantly rural masses, and the agents of this change were not the "medical doctors" imbued with the technical finesse and rigor of modern medicine but were the millions of "barefoot doctors" mobilized from among the impoverished, often illiterate peasant men and women, selected by their communities based on their willingness to serve the communities, educated and trained utilizing the resources the communities could afford with active support of the state. The indigenous medical knowledge systems were 
integrated on an equal footing with the modern medicine at all levels of health care, primary, secondary, and tertiary; and the science underlying these systems was developed and made explicit. Many of the barefoot doctors were supported by the state to go on and become full-fledged medical doctors only to come back to serve their communities [36, 37]. Most importantly this development was purely home grown, placing reliance almost exclusively on the indigenous resources.

India's trajectory provides a study in contrast. The Bhore Committee, which otherwise made some laudable recommendations, many of which flowed from the recommendations made by the Dawson Committee and the Beveridge Committee reports produced in England in the years 1920 and 1942, respectively, for the development of health services in the country, put its bet on "production of only one and that most highly trained type of doctor, which we have termed the "basic" doctor" (graduate of modern medicine) [1, Page 340]. As opposed to this the committee on "national health" of the "National Planning Committee" of the Indian National Congress proposed the following. "If medical advice and treatment to the mass of the people is [sic] to be provided on the necessary scale free of charge, the National Plan will have to bring the indigenous Vaidya, Hakim, or Dai into line with more elaborately or pretentiously trained physician or surgeon, gynecologist or obstetrician" [38].

That the rulers privileged the gold standard "basic doctor" over the latter could not have been without consequences; after all, which class of people could access and afford the opportunities to reach such a gold standard?

Mudaliar Committee opined "integration of Modern Medicine and Ayurveda is eminently desirable and all steps towards achieving that end should be promoted. Such integration should result in the development of a system of medical knowledge and practice based on all the best that is available in Modern Medicine and in Ayurveda" [39, Page 457]. But that such statements were meant for public consumption is evident from the assertion that "Participation in international health activities requires that the national health service in India should be based on modern medicine; ... the core of India's health service must continue to consist of persons adequately trained in Modern Medicine" [39, Page 458].

The policy proactively sought to make medical education the exclusive preserve of the well off. The Mudaliar Committee that followed the Bhore Committee endorsed the "opinion of the conference of principles of Medical Colleges that English should continue to be the medium of instruction in the medical colleges" [39, Page 327]. A further reflection of the mindset of the policy planners is evident from the following comment in the Mudaliar Committee report:

"reservation for scheduled castes and backward communities, which is incumbent under the Constitution, have all tended to limit the number of well-qualified students being admitted to colleges" [39, Page 317].

Neither in 1960, when the Mudaliar Committee came out with its report, nor even today the vast multitudes of the working masses in India is endowed with proficiency in English language and indeed the worst of sections among them belong to the scheduled castes and the scheduled tribes. Hence, it is only the English speaking, urban based rich upper class, upper caste students who can aspire for the commanding positions in the health services/Health Policy System of the country or, for that matter, in any other field of governance or white collar professions.

This automatically divides the population into two sections: a miniscule minority of the well-endowed, urbane, civilized, intelligent, capable and meritorious herd of technocrats, bureaucrats, judiciary, industry captains, officers of the armed forces, doctors, engineers, academics, and so forth upon whom falls the task of caring for, tending, educating, civilizing, and developing the vast multitudes of the laboring poor who are deemed to be capable of doing little else than sell their labor. Much less than harness the energy and the potential of the poor to take their destiny in their own hands, such an institutionalized demarcation of the people places the downtrodden in perpetual positions of dependency. The "White Man's Burden" thus turned into the "Brown Sahib's Burden."

Elitism is not just a matter of social status or class one belongs to, but also how one conceptualizes the problems and their solutions. For the elite who came to occupy dominating positions in the health systems hierarchy of the country, setting up large tertiary care hospitals and medical colleges with sophisticated machinery/technology was a far greater priority than setting up primary healthcare centers and subcenters in rural areas; they had greater faith in technology driven vertical disease control programs, often imposed by international donor agencies, as an instrument of eliminating diseases rather than the general health systems strengthening down to the village level as the strategy of choice to overcome morbidity and mortality [40]. Banerji writes that the rulers quoted the recommendations of the Bhore Committee, often out of context, to draw legitimacy for their own plans to "establish a very large number of medical colleges with sophisticated teaching hospitals in urban areas. They also invoked the Bhore Committee to justify setting up an even more sophisticated All India Institute of Medical Sciences in New Delhi on the model of the Johns Hopkins Medical Centre of U.S.A (quoting Mudaliar committee report, Vol I, p 191 [39]). A number of other postgraduate centers for medical education were also set up in due course. It however, took them over seven years even to start opening primary health centers to provide integrated curative and preventive services to rural populations of the country. These primary health centers were a very far cry from what was suggested by the Bhore Committee" [41].

There is at times a tendency to get swayed by the "socialist" notions and phrase mongering regarding the leading role of the state in healthcare that were sought to be appendaged to these policies. With the benefit of hindsight, one can say that the great power rivalry of the bipolar world afforded our rulers the luxury of appropriating notions of welfarism unto themselves even as they persistently pursued policies to favor the big capital and the semifeudal forces in the country. The relative shifts between the left and the right in terms of 
policies were guided more by the desire to extract concessions from one or the other super power. However, the demise of Soviet Union has rendered the true nature of our ruling elite explicit, especially with the attendant ascendency of the neoliberalism as the dominant economic and social policy since early 1990s.

4.2. Elitist Medical Education. Banerji mentions two diametrically opposite social objectives of medical education: firstly, "to ensure that educational system prepares physicians who are specially molded to serve the requirements of the country" and, secondly, "to train professional physicians who are well versed with the knowledge of modern medicine in its most sophisticated forms and who are trained mostly to provide services to those who can afford to pay for such services" [42].

Tables 10 and 11 help us decipher which of the two social objectives has been met by the medical education system in this country. With concerted efforts to bring about "structural corrections" in the rural healthcare system in the country through NRHM, the doctors per 1000 population ratio in the country have barely gone up from .03 to .05. The total number of doctors available to serve more than 833 million rural population in the country in 2011 was a measly 45,062 while, in 2007 , this figure was only 27,725 . It is sobering to note that, in 2007, the number of Indian medical graduates working in the USA alone was more than 50,000 when the population of the USA was just above 300 million.

AIIMS, the medical institute modeled along the lines of John Hopkins Institute to train the model modern doctors for India, has indeed led from the front in bolstering the trend of migration of Indian doctors to greener pastures in the West. From 1989 to 2000, nearly 54\% of the medical graduates from the institute migrated out of the country. From within these graduates, also, the ones from more well to do social backgrounds (the general category graduates were twice more likely to migrate than those coming from reserved categories) and the ones who performed better academically had a $35 \%$ greater chance of migrating compared to those who performed not so well [43].

Of the remaining graduate doctors in the country, nearly $74 \%$ live in urban areas serving a mere $28 \%$ of the population [44], assuming that the urban poor have the wherewithal to access their services. The elite capture of medical education has meant that doctors being produced in the country are largely from the privileged sections of the bigger cities. Present medical education inculcates in them an affiliation for technology driven costly curative care in the increasingly corporatized healthcare of the cities in India or the western shores. The rather drab illnesses of the rural folk that have their origins mainly in their poverty and malnutrition naturally fail to attract attention.

The careerist and commercial motivations inherent in such an education naturally undermine the more holistic concerns like the impact of poverty, caste, class, gender, and ethnic discrimination on health. This situation can only worsen further due to increasing commercialization of higher education that has already made it almost an exclusive preserve of the rich. There have been murmurs of "reorienting" medical education and improving the clinical skills of medical graduates to address the health needs of the poor. However, these promises have proved illusionary till now.

4.3. Rural Urban Dichotomy in Health Services. It is in the nature of the systems based on exploitation that the backyards of exploitation be maintained to preserve the privileges of the privileged. Greater concern for the government is to first satisfy the needs of the urban elite. It is little wonder then that while the more affluent sections of the rural society have gained upward mobility and have managed to come closer to affording the amenities of the cities, including expensive curative facilities, but largely speaking, the colonial paradigm of rural urban dichotomy in provision of health services has continued till this day.

CEHAT (Center for Enquiry into Health and Allied Themes) undertook an exercise to disaggregate the health budget allocated to rural and urban areas from the finance accounts of five states from different parts of the country for the year 2002-03. The results are shown in Table 12.

In the rural urban distribution of health budget, it is noteworthy that, with the exception of Mizoram, in no other state is the rural health budget allocated in proportion to the size of the rural population which by far is much more than the urban population. Secondly, it may be noted that rural health budget is predominantly constituted of family welfare budgets, while, for the curative care, the budget is heavily loaded in favor of urban areas. It is our villages that are the forte of poverty, caste, illiteracy, malnutrition, and disease. Apparently, our planners are concerned about the proliferation of this population, hence, the need for increased allocation for family planning, whatever may become of the slogan, "development as the biggest contraceptive." Even if we were to disregard the concerns for functionality of rural beds, Table 13 further shows the preponderance of curative facilities in the urban areas, meaning thereby that rural urban dichotomy is intertwined with what may be called the curative-preventive dichotomy.

\subsection{Curative-Preventive Dichotomy in Health Services.} Beginning with Chadwick's sanitary reforms in England, the history of modern medicine is replete with evidence of how preventive measures have played a defining role in man's continuing struggle against disease, resulting in elimination of many diseases as public health problem in the industrialized West. Much later, countries like China and Cuba showed the way to improve the health of entire populations by prioritizing disease prevention through comprehensive public health measures and at a cost that is a fraction of spending otherwise incurred on cost intensive technological interventions.

In India, we seem to have learnt the lessons the other way around where medical technologies have become a substitute for taking action on more basic issues like water, sanitation, and nutrition. For example, the massive "Pulse Polio Program" has been pushing unprecedented doses of polio vaccine, disregardful of its impact on the disease epidemiology, while it has nothing to offer as regards intervening 
TABLE 12: Rural urban inequities in public health expenditure of selected states for the year 2002-03.

\begin{tabular}{|c|c|c|c|c|c|c|c|c|}
\hline State/Type of expenditure & & Medical care $^{*}$ & Public health & Family welfare $^{\#}$ & $\mathrm{MCH}$ & Capital $^{* *}$ & Total & Rural/Urban population \\
\hline \multirow{2}{*}{ Maharashtra } & Rural & $5.71 \%$ & $60 \%$ & $49.97 \%$ & $60 \%$ & $0.78 \%$ & $32.51 \%$ & $66.57 \%$ \\
\hline & Urban & $94.29 \%$ & $40 \%$ & $50.03 \%$ & $40 \%$ & $99.2 \%$ & $67.49 \%$ & $42.43 \%$ \\
\hline \multirow{2}{*}{ Mizoram } & Rural & $51.9 \%$ & $51 \%$ & $63.87 \%$ & $51 \%$ & $100 \%$ & $55.68 \%$ & $50.47 \%$ \\
\hline & Urban & $48.1 \%$ & $49 \%$ & $36.13 \%$ & $49 \%$ & $0.00 \%$ & $44.32 \%$ & $49.53 \%$ \\
\hline \multirow{2}{*}{ Orissa } & Rural & $46.89 \%$ & $80 \%$ & $90.20 \%$ & $80 \%$ & $53.4 \%$ & $58.89 \%$ & $85.01 \%$ \\
\hline & Urban & $53.11 \%$ & $20 \%$ & $09.80 \%$ & $20 \%$ & $46.5 \%$ & $41.11 \%$ & $14.99 \%$ \\
\hline \multirow{2}{*}{ Punjab } & Rural & $42.47 \%$ & $66 \%$ & $65.46 \%$ & 0 & 0.00 & $45.00 \%$ & $66.08 \%$ \\
\hline & Urban & $57.53 \%$ & $34 \%$ & $34.54 \%$ & 0 & $100 \%$ & $54.60 \%$ & $33.92 \%$ \\
\hline \multirow{2}{*}{ Tamil Nadu } & Rural & $18.96 \%$ & $54 \%$ & $73.07 \%$ & $54 \%$ & $75.0 \%$ & $35.01 \%$ & $55.96 \%$ \\
\hline & Urban & $81.04 \%$ & $44 \%$ & $26.49 \%$ & $44 \%$ & $24.7 \%$ & $64.66 \%$ & $44.04 \%$ \\
\hline \multirow{2}{*}{ Madhya Pradesh } & Rural & $39.47 \%$ & $73 \%$ & $72.80 \%$ & $73 \%$ & $90.6 \%$ & $50.03 \%$ & $73.54 \%$ \\
\hline & Urban & $60.53 \%$ & $27 \%$ & $27.17 \%$ & $27 \%$ & $9.34 \%$ & $49.96 \%$ & $26.46 \%$ \\
\hline
\end{tabular}

Source: CEHAT, 2006 [10]. ${ }^{*}$ Including health services both allopathy and other system of medicines, minor head includes ESIS, medical education department drug manufacture; ${ }^{*}$ excluding MCH Program; ${ }^{* *}$ including capital expenditure of medical, public health, and family welfare. Proportions of rural and urban population are taken from CBHI, 2005 [11]. Note: demarcation for the rural and urban health budget was done from finance accounts 2002-03 for respective states. For about two-thirds of the expenditure, there is a clear rural-urban indication in the budget; for the rest, CEHAT used their functional knowledge of program implementation to allocate proportions to rural and urban areas.

TABLE 13: Number of government hospital beds in rural and urban areas.

\begin{tabular}{|c|c|c|c|c|}
\hline State & Rural hospital beds (government) & Urban hospital beds (government) & Total beds (government) & $\begin{array}{l}\text { Proportion of } \\
\text { rural and urban } \\
\text { beds }\end{array}$ \\
\hline Bihar & 1830 & 16686 & 18516 & $10: 90$ \\
\hline Chhattisgarh & 3270 & 6158 & 9428 & $35: 65$ \\
\hline Jharkhand & N.A. & N.A. & N.A. & N.A. \\
\hline Madhya Pradesh & 10040 & 18493 & 28533 & $35: 65$ \\
\hline Odisha & 7099 & 8715 & 15814 & $45: 55$ \\
\hline Rajasthan & 13754 & 12236 & 25990 & $53: 47$ \\
\hline Uttar Pradesh & 15450 & 40934 & 56384 & $27: 73$ \\
\hline Uttarakhand & 3746 & 4219 & 7965 & $47: 53$ \\
\hline EAG states & 55189 & 107477 & 162630 & $34: 66$ \\
\hline Non-EAG states & 114673 & 511187 & 622310 & $18: 82$ \\
\hline All India & 169862 & 618664 & 784940 & $20.5: 79.5$ \\
\hline
\end{tabular}

Source: GOI, $2011[12]$.

in the principle mode of transmission of polio that is fecooral transmission through contaminated water supply $[45,46]$. Tackling the later would have benefits for host of other public health problems like diarrheal diseases, typhoid, and malnutrition. Likewise, the Revised National Tuberculosis Control Program (RNTCP) has placed its bet only on providing DOTS (directly observed therapy short course) while leaving untouched the conditions that give rise to tuberculosis. The result has naturally been a rising mortality due to TB [47] and an increasing morbidity due to multidrug resistant tuberculosis [48]. Undermining disease prevention only leaves us to tackle greater burden of morbidity and mortality at later stages and thereby bringing the curative facilities under severe strain.

Table 14, based on figures given in Table 3.7, National Health Accounts of India, 2004-05, gives the health expenditure by different ICHA (International Classification of Health Accounts) functions. Of the total health budget, the preventive functions command barely 20.78 percent of the budget while curative services corner close to 50 percent of the budget. The relatively higher proportion of preventive health care spending of the central government is on account of the fact that all the "National Disease Control Programs" are funded by the center.

Nutrition program is included in "Health and Related Functions" but has been mentioned separately over here on purpose. It would hardly be an exaggeration to say that that "food is the basic medicine of public health" and yet, at conceptual and programmatic level, the health planners seem to have completely divorced themselves from this fact. It is true that there are supplementary nutrition programs run by other departments of the government, but should that be the reason why health policy establishment should almost give up on such a fundamental aspect, the impacts on the health of the people as nothing else does, only to focus on narrow technocentric approaches to alleviate the health problems of the people? It is anybody's guess as to the efficacy of complete immunization in a malnourished child. 
TABLE 14: Health expenditure by ICHA functions, National Health Accounts, 2004-05.

\begin{tabular}{|c|c|c|c|c|}
\hline & \multirow{2}{*}{ Health care function } & \multicolumn{3}{|c|}{ Proportion of budget spent } \\
\hline & & Center* & State & Total \\
\hline HC.1 & Curative care & $22.16 \%$ & $46.92 \%$ & $42.67 \%$ \\
\hline HC. 2 and 3 & Rehabilitative and long term nursing care & $1.02 \%$ & $0.13 \%$ & $0.28 \%$ \\
\hline HC. 4 & Ancillary services related to medical care & $1.46 \%$ & $2.50 \%$ & $2.33 \%$ \\
\hline HC. 5 & Medical goods dispensed to outpatients & $2.01 \%$ & $0.69 \%$ & $0.92 \%$ \\
\hline Subtotal & Curative health care services & $26.65 \%$ & $50.24 \%$ & $46.2 \%$ \\
\hline \multirow{5}{*}{ HC.6 } & \multicolumn{4}{|c|}{ Prevention and public health services } \\
\hline & $\mathrm{RCH}$ and family welfare & $24.23 \%$ & $9.55 \%$ & $12.07 \%$ \\
\hline & Control of communicable diseases & $14.64 \%$ & $5.20 \%$ & $6.82 \%$ \\
\hline & Control of noncommunicable diseases & $01.63 \%$ & $0.76 \%$ & $0.91 \%$ \\
\hline & Other public health activities & $1.24 \%$ & $0.93 \%$ & $20.78 \%$ \\
\hline Subtotal & Preventive health care services & $41.74 \%$ & $16.44 \%$ & $20.78 \%$ \\
\hline \multirow[t]{2}{*}{ HC.7 } & $\begin{array}{l}\text { Health administration and insurance; health and } \\
\text { related functions (medical education and training } \\
\text { of health personnel, research and development, } \\
\text { capital formation, and food adulteration control); } \\
\text { functions from other sources; and functions not } \\
\text { specified. }\end{array}$ & $31.61 \%$ & $33.21 \%$ & $31.86 \%$ \\
\hline & Nutrition program & - & $0.10 \%$ & $0.08 \%$ \\
\hline Subtotal & $\begin{array}{l}\text { Health functions other than curative and } \\
\text { preventive }\end{array}$ & $31.61 \%$ & $33.31 \%$ & $31.94 \%$ \\
\hline Total & & 100 & 100 & 100 \\
\hline
\end{tabular}

Source: GOI, 2004-05 [13].

Note: ${ }^{*}$ is related to Ministry of Health and Family Welfare only.

(1) Services of curative care include expenditure on teaching hospitals, specialty hospitals, ESI dispensaries, homeopathic hospitals and dispensaries, ayurvedic hospitals and dispensaries, and primary health centers, community health centers, and expenditure on dental care.

(2) Rehabilitative care includes expenditure on rehabilitative centers for TB and leprosy patients, institute for rehabilitation of physically handicapped, and drug deaddiction programs.

(3) Ancillary services related medical care includes expenditure on blood banks, blood transfusion council, regional diagnostic centers, ambulance related expenditure, and medical store depot.

(4) $\mathrm{RCH}$ and family welfare covers expenditure on $\mathrm{RCH}$ and family welfare programs.

4.5. Market Led Growth of Health Care in India. There is a large body of literature internationally and from India [27, 49-55] that attests to the devastating effects of market led growth of healthcare. The biggest blow that globalization has delivered to healthcare systems is that it uprooted healthcare from its moorings in "social justice" and "service" to humanity and legitimized it as a source of extracting profits. As already mentioned above, this paradigm shift governs not only the private sector but has extended to the public sector healthcare in form of commercialization of its components/ services. Paradoxically the public sector has proved to be a supporting pillar for private health care in the country. Public sector medical colleges contributed hugely to the growth of the private sector with 80 percent of the doctors passing out of these colleges either joining the private sector or migrating abroad [53, Page 24].

Even though the private healthcare always constituted larger part of the healthcare system in India, with the advent of globalization, big corporate houses entered into healthcare provisioning and have increasingly came to influence health policies and set standards of care that are far removed from the real life conditions of common Indians. Private sector constitutes eighty percent of the health sector in India [56]. Corporate healthcare is pushing high end technologies in both diagnostics and treatment irrespective of their desirability for the profile of public health problems in India. Additionally, pushing of unjustifiable high end technologies is a drag on precious public resources for health in the form of either direct or indirect tax concessions on their import and operation and through public-private partnerships doled out to the private sector.

Now, there is talk of the government turning itself into net purchaser of curative healthcare from the private sector while restricting itself to providing a small package of preventive services. This has been euphemistically termed as "managed care" [57]. Imposition and successive escalation of "user charges" levied for the services of publically financed health institutions is another feature of neoliberal economic policies that is the bane of the poor [58]. User charges have been beaten back to the extent people have forced the governments, through their struggles, to do so. The latest 7th Common Review Mission Report, which went into the implementation of National Rural Health Mission (NRHM) in different states, says that the governments in the states of Kerala and 
Jharkhand have withdrawn user charges from public facilities [2].

With corporate healthcare becoming the "prima donna" of healthcare industry in the country, this has consequences for the motivation of public sector health workers in dedicating themselves to the more holistic motives of public healthcare. Motivation of workers critically impacts the performance of health sector since efficiency, equity, and service quality, all, are directly transacted by the willingness of the workers to dedicate themselves to their tasks [59]. Apart from individual level determinants, worker motivation is determined by "organizational (work context) level, and determinants stemming from interactions with the broader societal culture" [59].

The "broader societal culture" of healthcare today is being tempered by the commercialized ethos of private healthcare. For example, while the healthcare system allows (implicitly or explicitly) a number of extraneous incentives, varying from systems of commissions from private diagnostic labs to outright bribes by drug and medical equipment manufacturers for the doctors, not because of the work that they may do towards furthering patient care but because of the position they occupy in the medical system, similar opportunities, however, are not available to the other categories of hospital staff, who may then feel tempted to resort to more crude and direct extraction of money from the patients.

In either case, personal aggrandizement becomes the desired social objective and any improvement in the societal wellbeing becomes contingent upon the fulfillment of the former. These are not inadvertent outcomes but are the result of the policies that have been pursued over the years. Developing markets in healthcare have become the conscious objective of the economic and health policy of the state. Today, the price for which the private sector plucks top notch consultants from the public hospitals is considered a measure of the doctor's professional capabilities. The government, on its part, feigns helplessness in spite of the fact that it spent a considerable sum of people's money in, first, training these consultants and, then, providing them with the facilities of public hospitals to hone their clinical skills. The private sector gobbles up the talent for virtually no cost to it.

Another insult to injury that has been added during the implementation of the neoliberal economic policies since the beginning of the 1990s has been the large scale hiring of the contractual staff at all levels for work profiles that are perennial in nature. The contract paramedical and medical staff feels exploited even as they do more work compared to the regular health workers for lesser remuneration and facilities. Such medical and paramedical health workers hardly visualize their future with the growth of the public hospital or public health system. For them, such an engagement is a stop gap measure which they must utilize for maximizing personal welfare rather than the welfare of their patients.

In all these years, there has not been a single study to show that hiring staff on contractual basis has helped in increasing the patient care or efficiency of the hospitals. Yet the myth keeps getting reinforced that contractual staff can be made to work better than the regular staff, because it suits the convenience of the government and the administrators.
The "private medical sector" has proved to be the proverbial "camel" that has pushed the Arab (the "public medical sector") out of the tent.

4.6. Deficiency of Political Will. As goes the adage-“where there is a will, there is a way"; equally true is our contention"where there is no will, there are alibis and subterfuge, albeit in the form of elaborate schemes." No government in India since 1947 transfer of power has failed in expressing its solidarity with the Indian masses in terms of alleviating their suffering. On the face of it, they still remain committed to increase welfare spending cutting across political spectrum. However, failure to achieve, till date, even the goals and targets laid out for the first ten-year period after independence in the Bhore Committee Report is equally eminent.

In 1977, the India's ruling classes committed themselves to the Alma Ata Declaration on achieving "Healthcare for All by the year 2000" through the strategy of "primary health care." No sooner than this commitment was made that our ruling elites jumped on to the bandwagon of "selective primary health care" that was sponsored by the American foundations and multinational vaccine corporations. The year 2000 came and went, but the goals of neither the "primary health care" nor its "selective" variant were achieved.

In 2002, the then Bhartiya Janata Party led National Democratic Alliance government at the Centre came up with the "National Health Policy." This was followed soon by the "National Common Minimum Program" of the first "United Progressive Alliance" government at the Centre that was eminently supported by the Parliamentary Left in 2004. The "National Health Policy, 2002" and the "Common Minimum Program" of the first "United Progressive Alliance" government at the Centre promised to increase the health spending to a level of 2 to 3 percent of the GDP by 2010 [60]. A huge program for the renewal of rural health care in the country was launched in the form of National Rural Health Mission (NRHM) in 2005. Having finished its first phase of seven years in 2012 without having been able to achieve even one of the goals set before it, NRHM is now into its second phase. Yet the pious objective of taking the public health expenditure in the country to 2 to 3 percent of the GDP continues to evade the country.

At the time of rolling out the process of preparing their "Program Implementation Plans" (PIP) for the implementation of NRHM during the financial year 2013-14, the states were instructed that they could increase their expenditure under NRHM up to 30 percent over the baseline of 2012-13. However, the economic slowdown hit back in the meanwhile and, by the time of actual allocation of central assistance to different states, the officials of the Ministry of Health and Family Welfare bluntly told the states that no increase in allocation would be possible (the author was privy to these developments while working as a consultant with National Health Systems Resource Center, Government of India).

Apart from indicating the financial resources committed for health, the health budget is also the single most important measure of the political commitment of the rulers to improve the health of the people. Government's backing off from offering even a very modest increase in the budget for rural 
TABLE 15: Cuba's total government expenditure and expenditure on social services (including health) and defense during the special period (in millions of current Cuban Pesos).

\begin{tabular}{lccc}
\hline Year & Total government expenditure & Expenditure on defense/internal order & Expenditure on social services (education and health) \\
\hline 1989 & 14041 & $1269(9.04 \%)$ & $2576(18.35 \%)$ \\
1990 & 13852 & $1120(8.1 \%)$ & $2492(18.00 \%)$ \\
1991 & 15436 & $925(6.0 \%)$ & $2548(16.50 \%)$ \\
1992 & 14312 & $746(5.2 \%)$ & $2395(16.70 \%)$ \\
1993 & 12564 & $615(4.9 \%)$ & $2123(16.90 \%)$ \\
1994 & 10035 & $461(4.6 \%)$ & $1696(16.90 \%)$ \\
1995 & 8866 & $392(4.42 \%)$ & $1584(17.90 \%)$ \\
1996 & 8326 & $323(3.9 \%)$ & $1697(20.4 \%)$ \\
1997 & 8368 & $421(5.03 \%)$ & $1797(21.50 \%)$ \\
1998 & 8344 & $343(4.1 \%)$ & $1823(21.80 \%)$ \\
\hline
\end{tabular}

Source: based on data given in Table V, Dunning, 2001 [14].

TABLE 16: India's total government expenditure and expenditure on social services (including health) and defense during the economic crisis of early 1990s (in billion current Rupees).

\begin{tabular}{lccc}
\hline Year & Total government expenditure & Defense expenditure & Social services expenditure \\
\hline $1989-90$ & 929.08 & $144.16(15.5 \%)$ & $30.61(3.3 \%)$ \\
$1990-91$ & 1052.98 & $154.26(14.6 \%)$ & $32.74(3.1 \%)$ \\
$1991-92$ & 1114.14 & $163.47(14.7 \%)$ & $35.69(3.2 \%)$ \\
$1992-93$ & 1226.18 & $175.82(14.3 \%)$ & $40.09(3.3 \%)$ \\
$1993-94$ & 1418.53 & $218.45(15.4 \%)$ & $48.30(3.4 \%)$ \\
$1994-95$ & 1607.39 & $232.45(14.5 \%)$ & $58.73(3.7 \%)$ \\
$1995-96$ & 1782.75 & $268.56(15.1 \%)$ & $76.55(4.3 \%)$ \\
$1996-97$ & 2010.07 & $295.05(14.7 \%)$ & $96.72(4.8 \%)$ \\
$1997-98$ & 2320.53 & $352.78(15.2 \%)$ & $118.45(5.1 \%)$ \\
$1998-99$ & 2793.4 & $398.97(14.3 \%)$ & $146.56(5.2 \%)$ \\
\hline
\end{tabular}

Source: based on figures taken from Tables 103 and 104, RBI, 2012-13 [15].

healthcare in the country at the first whiff of an economic slowdown, even as it continues to offer tax exemptions to the most wealthy in the country to the tune of lakhs of crores of rupees, shows the shakiness of their political commitment to the welfare of the people.

As to the possibility of doing things differently, we present the comparison between Cuba and India to underscore what political commitment to health care means. It is well known that Cuba went through a sudden and catastrophic economic crisis in the early 1990s due to the collapse of the Soviet Union and, along with it, the collapse of preferential trade and economic aid Cuba received from the Soviets. The Cuban economy contracted suddenly and rapidly. These are the kind of trying circumstances that test the commitment of governments to ensure human well-being as reflected by the resources committed for the same. Generally speaking, the experience is that, in times of economic crisis, expenditure on welfare (health, education, and food) is the first to come under knife, precisely, at a time when the people, especially the poor, need greater protection.

Beginning 1990s, India also faced an onerous economic crisis which queered the pitch for neoliberal economic reforms in the country. Tables 15 and 16 present the response of the governments of Cuba and India towards ensuring human welfare under such trying circumstances. After the economic crisis, during the special period, the total government expenditure declined continuously till 1998 in comparison to the base year of 1989, except for a marginal increase in 1991 and 1992. There was also an absolute decline in expenditure on social services, almost continuously till 1994, after which the absolute budgetary allocation for social services started increasing once again even though the total budget of the government was still contracting in comparison to that of the base year. As a proportion of total government expenditure, however, expenditure on social services started recovering from 1992 itself. The budget on social services varied between 16.5 and nearly 20 percent. Cuba severely compromised on its defense budget which reduced from 9.04 percent of the total government expenditure in 1989 to 4.1 percent in 1998. This is exceptional given the geopolitical situation of Cuba, especially at a time when it was most vulnerable to US hostility.

With respect to India, the situation is almost the reverse. Our defense expenditure has consistently varied between 14 and 15.5 percent during the 1990 s, whereas expenditure on social services hovered between 3 and 5 percent. 


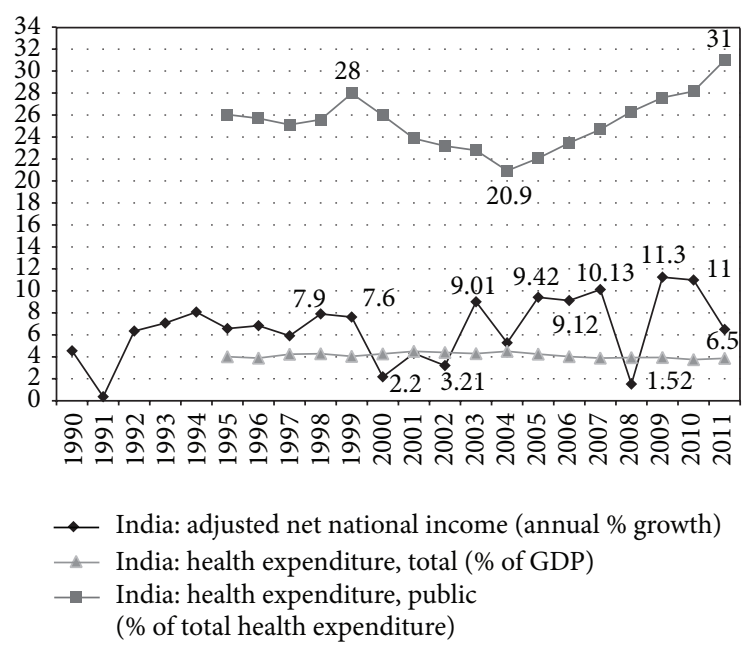

FIGURE 4: Variation in India's health expenditure with GDP growth rate. Source: all the figures have been obtained from Health Nutrition and Population Statistics in World Bank DataBank. Available at http://databank.worldbank.org/data/views/variableselection/ selectvariables.aspx?source=health-nutrition-and-population-statistics since 15th August 2013.

Figure 4 shows that India's public expenditure on health reached its nadir in 2004 when it accounted for barely 21 percent of the total health expenditure. Between 2004 and 2011, this proportion increased from 21 percent to 31 percent, which can easily be attributed to NRHM. However, the overall impact of this increase can be judged from the fact that it has made little difference to the overall expenditure on health in India. In fact, there is a slight negative slope between 2004 and 2011 in the graph as regards this. What is particularly noteworthy is that the phenomenally high economic growth rates observed in the country during 1990s and 2000s seem to have made little difference to the overall resources being committed for health. An increase of 10 percent in public expenditure as a proportion of total expenditure on health is too little too late and even this could well be set to suffer rollback in face of economic uncertainties that currently face the country.

\section{What Are the Solutions to Alleviating These Challenges?}

Before we go on to discuss the possible solutions to the crisis under discussion, one has to be a bit discerning regarding what is remediable and what is remediable and what is not under the given social, political, and economic system in the country. Tackling factors like class character of the ruling elite and their orientation towards development issues is a far more complex issue that can hardly be remedied by some policy initiatives. The policy orientation of the ruling classes also depends on larger global geopolitics. Bringing about a longer lasting change in their character, however, entails a political process which is beyond the pale of our discussion here, except that an understanding of these issues enables us to make realistic assessments and policy choices that are feasible, besides aligning ourselves with the larger processes of political change. As a corollary, it also follows that even the most liberal of the policy regime that can be pursued in the given system shall constitute only a partial solution of the crisis. However, even these partial solutions are worth pursuing in so far as they hold the promise of bringing some relief to the people from the present neoliberal policy regime.

Having placed this caveat we can say that the policy instruments to improve the functioning of the public hospitals cannot but flow from an understanding of the consequences of the factors that constitute the crisis and their social and political origins. The solutions would essentially lie in instituting policies that would reverse these consequences.

The most fundamental premise underlining these solutions is that the provision of food, health care, water, sanitation, and education, the most important factors impacting on health outcomes, ought to be ensured as a matter of right, free from profit motives. Further, only such measures can be acknowledged as solutions that are primarily responsive to epidemiological needs of the patients, rather than those that suit the exigencies of the health administrators.

It would be worthwhile to point out here the experience of India's biggest and most reputed public health institutionthe All India Institute of Medical Sciences (AIIMS).

The doctors at AIIMS have been complaining since long that the huge daily rush of patients in the institute's outpatient department not only has worsened the standard of clinical care at the hospital but also leaves hardly the faculty with time to concentrate on medical research and teaching. This is defeating the most important role that the institute is supposed to perform - that of setting up model of patient care and medical teaching in the country.

While one can be at variance with the models they may have in mind, this is a perfectly legitimate concern of the faculty and administration at AIIMS. However, in response to this, various departments have arbitrarily decided to limit the number of patients registered daily in their outpatient departments. While this may have been expedient for institute administration to get over its problem, the remedy has turned out to be the quintessential double whammy for the patients who come from far corners of the country to seek treatment at AIIMS. Meanwhile, it seems unlikely that this solution will change things in any meaningful way. To the contrary, some senior doctors discovered (as personally told to the author) that this "solution" resulted in outpatient cards being sold at high premium by some unscrupulous employees.

Worse still, developing models for excellence inpatient care or for medical research in the country do not seem to be the important motivation behind such decisions. Most of the doctors have been passive in opposing the commercialization of services of such institutions or in opposing attempts at privileging industry interest in their research. Doctors have been raising their economic demands but invariably fail to demand alternative strategies that are expedient in tackling the high patient load or raise the issue of reinvigorating the peripheral healthcare institutions such that institutions like AIIMS do not end up performing the functions of general hospitals. In fact, the height of cynicism on these issues can be judged from a comment made by a senior ex-faculty-member 
of the institute in a conversation with the author. While lamenting over falling standards of patient care due to huge patient load, he went as far as to suggest the following: "let the patients die (due to limited registration of the patients), but the Institute must not let its standards be diluted." It is not our assertion that this is a view generalizable to all doctors at AIIMS; but this does certainly show how retrogressive the sentiment can get.

5.1. Suggestions for Reinvigorating Peripheral Services and Improving the Services of Public Hospitals. The challenges that confront functioning of public hospitals are vexed and, as such, cannot be addressed in their entirety within the development paradigm of the present ruling classes which has its roots in the class character of the Indian state. A comprehensive redress of the issues raised above shall entail nothing short of the remaking of the Indian state itself, which is a political process and, as such, is out of the scope of this paper. Accordingly, the possible solutions suggested here concern with policies that can provide some relief under the present conditions. This too goes with the caveat that the arraignment of political forces internationally and nationally, as it obtains today, does not forebode well even for these policy changes, which should, otherwise, have been possible in a liberal bourgeoisie framework of a welfare state. This only highlights the primacy of the political task mentioned above; howsoever much, we may disagree with it.

\subsubsection{For Rejuvenating Peripheral Health Services}

(i) The task of making the primary and secondary level health institutions functional ought to be the utmost priority, such that people can access effective healthcare for common and easily treatable conditions nearest to their homes.

(ii) Urgent steps need be taken to provide working and living conditions in the peripheral areas that will encourage doctors and other health personnel to be willing for rural service. Family hostels should be built in the nearby urban centers to house the families of doctors and other medical personnel, while they are posted in remote areas. State should ensure admission of their children in best schools in the area and other such facilities. It may be noted that such steps are routinely taken in the case of defense personnel.

(iii) All the vacancies for medical and paramedical posts should be filled promptly and the administrative procedures should facilitate speedier permanent appointments. There is little evidence to show that provision of ad hoc/contract appointments has led to a sustained availability of health personnel in rural areas.

(iv) Consequent to fulfillment of the aforementioned conditions, rural service should be made compulsory for health personnel of varying categories immediately after their graduation. There should not be waivers of any kind to allow the personnel to avoid doing such service. (v) A much greater reliance should be placed on the training of a large number of paramedical personnel or on reviving licentiate courses to fill in the gap in the availability of primary level healthcare.

(vi) The capacity of peripheral health services should be expanded to absorb the large number of health workers as full time workers in the health services system. Private practice for any category of workers should not be allowed.

(vii) There should be regular programs organized wherein the senior doctors from the secondary or tertiary level health facilities and medical colleges should mandatorily go to the rural areas to help the peripheral health workers improve their knowledge and skills.

(viii) Once these conditions are realized, certain administrative steps can be undertaken to ensure a proper referral system for the patients from the most peripheral to the tertiary level institutions.

(ix) The local communities, peoples organizations, and representative bodies should be involved in "the planning, organization, operation and control of primary healthcare, making fullest use of local, national and other available resources" in the true spirit of the "primary health care" as enunciated in the Alma Ata Declaration of 1977 [61]. However, it need be stressed here that unless a fundamental reordering is brought about in the power relations of caste, class, gender, and community in the rural society, such kind of control and participation shall only be exercised by the presently dominant sections of the rural society.

(x) Public hospitals associated with large institutes or medical colleges should be encouraged to further strengthen their outreach services.

(xi) In order to ensure that things work as they ought to, a system of accountability should be in place with the guiding principle, firstly, that responsibility has to be fixed for the most empowered functionary rather than the one which is least empowered and, secondly, that no system of accountability can be enforced through policing oversight as the principle mechanism. In order that people are willing to stand accountable, it is of utmost importance to provide working environment that harnesses people's enthusiasm to work as per their respective capabilities.

It need be emphasized here that it is the engrained logic of the systems based on exploitative relations of production to believe that people work either in response to fear of authority or for individual material incentives. The fact, that to work and to indulge in a socially productive work is a fundamental human want which is least recognized in such systems.

\subsubsection{For Improving Services at Public Hospitals}

(i) To reinvigorate the positive spirit of Bhore Committee, it need be stressed that national health organization ought to be a "whole time salaried service 
devoting itself to the development of the health of the people." Hence, the provision of allowing private practice by the government doctors should be banned forthwith.

(ii) For maximal utilization of the infrastructure of public hospitals, provision should be made for both morning and evening OPDs. The necessary staff, equipment, and space should be provisioned for running such clinics and diagnostic set-up. Evening OPDs shall have the added advantage of obviating "opportunity costs" for the poor who have to miss their daily wage to attend to the hospital in the morning. It may be noted that if the private hospitals or diagnostic centers can operate such facilities, why should it be difficult for a public hospital to do so?

(iii) A number of modern technologies have become available over the years to improve the functioning of public hospitals. The guiding principle for their use should be that these technologies should be used to maximize the patient welfare, rather than for curtailing patient services.

Diagnostic equipment, like autoanalyzers that are now available, have replaced the manual diagnostic processes and can be deployed to do laboratory investigations round the clock without necessarily having to deploy larger manpower as was necessary with manual processes. This can be most expedient in arriving at an early diagnosis of ailment and facilitate setting up of evening OPDs. Likewise, use of information technology for improving the hospital records; for example, the laboratory or radiological investigations can be uploaded on central portal such that they are readily available to those who have to use the results of the investigations. Such a measure can be very helpful in preventing harassment to the patients that they face in tracing their reports, often ending up wasting days on this without actual movement in the treatment that they seek.

(vi) Last but not the least, all measures directed at commercializing the use of hospital services through imposition of user fees on patients should be rolled back. These are highly inefficient in providing cross subsidies to the poor patients and have grave implications for equity and access to healthcare [58].

The World Bank was the chief proponent of the imposition of user fees in public health services throughout the world. However, addressing the 66th World Health Assembly at Geneva on 21st May 2013, the World Bank President Jim Yong Kim said:

"Anyone who has provided health care to poor people knows that even tiny out-of-pocket charges can drastically reduce their use of needed services. This is both unjust and unnecessary" [62].
5.2. Reversing the Market Led Growth of Healthcare. Market led growth of healthcare is part of the economic agenda of the ruling classes and is motivated by their "class interests" which are in antagonistic relationship with the "class interests" of the working masses. Besides harnessing healthcare as a source of profit, the interest of the ruling classes is to provide exclusive services for the affluent sections while relegating public health services to a secondary status. The interest of the overwhelming masses on the other hand lies in provisioning of universal healthcare as a "societal good" irrespective of the individual's ability to pay.

If there is willingness to search for policy options based on the empirical examination of different policies that have been implemented in different parts of the world in different contexts, as also in our own country over the last two decades, maybe there can be some scope of reasoning our way through to secure the interests of the common people. Unfortunately, as things stand today, such a possibility does not seem to exist.

The lack of political will on part of the government to act in the interest of the vast majority of poor people is linked to class interests of the people it actually represents. In other words, the question is of class struggle which is part of larger political process. Here, we can only reiterate the need to choose sooner than later the side on whose behalf we would like to pitch in, in this struggle.

As regards the government, it has made its intensions very clear by the fact that the Planning Commission rejected the "High Level Expert Group (HLEG) Report on Universal Health Coverage for India" that was instituted by the commission itself.

The report, while being agreeable to private sector involvement in health sector, had recommended "expansion and augmentation of primary healthcare, strengthening of district hospitals, expansion and upgrading the skills of the health workforce, free provision of essential medicines, abolition of "user fees", establishment of effective regulatory structures and support for active community participation as high priorities requiring early action" [63]. Apart from the recommendation of contracting out services to the private sector wherever necessary, HLEG made a recommendation in stating that "every citizen should be entitled to assured free access to a package of essential health services, which will be periodically defined by an expert body, through a national health entitlement card (India Health Card). Public facilities for healthcare will have to be the main delivery system of UHC" [63].

However, no sooner were these recommendations made by HLEG than the system struck back. World Bank is reported to have said, "There is a growing number of highquality, low-cost providers that may be willing to engage with the government in providing defined packages of care to the poor. Policies need to be in place to foster more effective engagement with the private sector" [64].

The Planning Commission was quick to put its emergency brakes on. In a meeting on 3rd February 2012, it briefed the PMO (Prime Minister's Office): “The HLEG excludes the possibility of contracting out of services to qualified providers ... With $80 \%$ of doctors, $26 \%$ of nurses, $49 \%$ of beds, $78 \%$ of ambulatory services, and $60 \%$ of inpatient care, the private 
sector has to be partnered with healthcare delivery" [65]. The representatives of private healthcare industry had this to say, "Specialty and super-specialty areas should be left to private sector since the government can afford neither the infrastructure nor the salaries to retain the talent required for tertiary care" [65].

These developments regarding HLEG recommendations, which in no way sought to establish "socialism" in the realm of healthcare delivery in the country, only point to the tenacity with which we need to pursue the propeople health agenda in the country.

5.3. Resolving the Question of Elitist Medical Education. As a measure of what is missing in our medical education today, we would like to offer the following quote from the Bhore Committee's report:

“... a social outlook should be developed in every health worker and that a spirit of emulation be cultivated throughout the rank and file of service ... Understanding and sympathy, tact and patience are equally important for the proper handling of these persons and, in their absence, mere professional skill will fail to achieve satisfactory results. On the other hand the possession of these qualities will lift the efforts of the health worker to the plane of social service" [1, Page 27].

There is an important task at hand, that of "demystifying" medical education. In order to make medical education an exclusive preserve of the elite, there is a cultivated notion that medicine, as a field of study, is so complex that only those with exceptional intelligence and "merit" can become worthy doctors. Above all, becoming a worthy doctor is a matter of having the aptitude to serve and that the real merit of a doctor does not lie as much in his/her being able to acquire medical knowledge, as much it does in his/her ability to translate this knowledge into practice in highly challenging circumstances of our people and in the generation of new knowledge. These two latter aspects have been totally sidelined in the manner of selection of medical students and their training.

Like other biological sciences, medical knowledge is more of factual than logical or conceptual, which means that, as far as acquiring medical knowledge is concerned, one can do so by putting in reasonable hard work, provided of course other impediments to accessing medical knowledge can be overcome. In our opinion there are four major impediments in this direction that need to be tackled forthwith.

\section{(i) Dual system of education.}

The roots of the elite capture of medical profession and indeed other professional courses lie in the dual system of school education in the country, costly English medium education for the elite, and poor quality of government schools teaching in vernacular medium. Education is not just about the medium of instruction, it is about inculcation of social, moral, and ethical values; it is about how one relates to and aspires to improve the society one lives in.
The top notch English medium schools in the big urban centers have become a preserve of the rich who seek an exclusivist education for their children.

So long as this class with exclusivist nurturing exists, they shall seek and also manage almost exclusive access to top positions in all walks of life including the polity, the bureaucracy, the judiciary, and higher education. This is a class that is least desirous of sharing its privileges with common citizenry of the country and is by far the most potent force in the reproduction of the system as it stands today. Hence, the dual system of education must go.

(ii) The present system of selection of medical graduates is as follows.

The present system of medical entrance examination with its emphasis on memorizing more and more obscure facts and correctly recalling them while answering the multiple choice questions should be done away with. Over the years, this system has spawned a whole industry of coaching institutes which provide this specialized training to crack the exams at prices that are invariably beyond the capability of even many of the middle class families.

A system of selection needs to be developed that will test basic intelligence of the aspirants; their aptitude for serving the people, especially the underprivileged; their understanding regarding social issues impacting on the health of the people; and other such factors. Such kind of a process could entail multilevel selection process with each step being designed to sieve in the most deserving candidates.

Towards this end, we learn from the historical examples that are available from post-1917 Soviet Union and preneoliberal reform China, but even the more contemporary examples like the "National Training Program for Comprehensive Community Physicians" (NTPCCP) in Venezuela [66].

(iii) Decommercialization of medical education is as follows.

In order that men and women and boys and girls from the subaltern sections can easily afford to get educated in medicine, medical education should be entirely free for all students with strict conditions built into the program that the student shall have to serve the underserved populations once their training is completed. Such conditions should not be bartered for monetary or any other kind of fines.

The upper age limit should be liberally relaxed to enable even older persons to undertake medical education. For candidates from working class or poor rural backgrounds, the government should provide maintenance allowance for the family such that these students can complete their education without having to worry for the needs of their families. Such measures have currently been undertaken in Venezuela as part of the NTPCCP. 
Such reforms in medical education would automatically disincentivize it for those candidates who look upon medicine as a lucrative career option and help in changing the class base of medical profession.

(iv) Changing the medium of instruction from English to the locally spoken languages is as follows.

In the Indian context, as perhaps might be true for many other developing countries, English is not just another language spoken by a certain section of people. It has come to represent a social class, is associated with certain social status and a cultural mindset, and above all is the language of governance in the country. All of this alienates overwhelming majority of Indians who do not have either the knowledge of the language or enough of a command over it, from vast areas of governance, higher education, and elite professions where English is the medium of transaction.

An impression is created that our education, especially technical education, shall lag behind the international standards if the medium of instruction were not to be English. One need only point out here that barring the Anglo-Saxon world, English is not the currency of academic exchange in large parts of the world like China, Japan, Russia, France, Germany, and the like; but can they be said to be lagging behind international standards?

We can devise some practical steps to make the transition as follows.

A national project should be instituted to translate/write medical books into local languages while retaining the English technical terms with or without the corresponding term in the local language. For example, gall bladder can remain gall bladder for instruction in all languages or the word enzyme can be retained as such.

Till such time that an Indian language can be developed to act as a truly pan Indian language, there will still be the need for imparting working knowledge of English or communication skills in it to all students such that medical professionals across the country can engage in a professional interaction.

While being discussed in the context of medical education, such measures need be initiated in almost all the disciplines of education. In fact, one such beginning has been made in the state of Madhya Pradesh that too by a right wing political force such as the BJP. The President Mr. Pranab Mukerjee laid the foundation stone of the Atal Bihari Vajpayee Hindi University at Mugalia Kot in the state on the 7th of June 2013. The university has been established with the promise of offering courses in medicine and engineering among others in Hindi [67]. It is to be seen, however, how far this move goes, but it is commendable to begin with.

Apart from the aforementioned measures another important policy thrust has to be-to bridge the gap between the medical and the paramedical branches of healthcare personnel. Policy measures should be devised to encourage the lower rungs of healthcare professionals like the nursing staff, ANMs, and community health workers to graduate to the higher levels. Necessary changes should be made in the medical curricula/courses to facilitate this.

A word need be said here regarding the "Rural Doctors" course that had been in discussion till sometime back. While being open to the desirability of such a course, we would caution that such a course should not end up being a "poor doctor" course for poor people and add another tier to the medical hierarchy. Instead, a possibility need be considered for devising a single uniform course at the undergraduate level that is much abridged and more focused on community level healthcare. The present M.B.B.S course incorporates too much of detailed information on many subjects that are of the best use to a specialist in those subjects rather than a public health physician. Subjects like forensic medicine can best be avoided at undergraduate level.

Our suggestions here are only suggestive. We are sure that if a systematic approach is taken in this direction, far more constructive opinions can come forth.

5.4. Resolving the Curative-Preventive Dichotomy. Curativepreventive dichotomy in health is intertwined with two aspects-the rural-urban dichotomy (preventive care for rural areas and costly curative care for urban areas) and the hierarchy between curative and preventive branches of medicine. While value of preventive medicine is little appreciated by people in the absence of disease, seeking care becomes incumbent upon falling ill and therein lies the higher market value of clinical disciplines. To this extent, clinical care serves as the convenient mode of profit generation. Hence, market driven growth of healthcare has widened the chasm between the clinical and preventive branches, thereby increasing the overall cost of improving people's health. Following policy measures can be helpful in bringing about a correction in this dichotomy.

(i) Overall development of public healthcare systems shall minimize the profit motive in medicine and can be expected to privilege application of preventive medical knowledge to reduce the overall cost of improving people's health.

To strengthen the curative care in rural areas by creating facilities that will encourage doctors and other paramedical personnel to accept postings in rural areas, government cannot shy away from providing decent boarding and lodging facilities for them besides taking care of the family needs like schooling of the children.

More and more training institutes for at least lower categories of paramedical staff should be located in the rural areas by upgradation of existing facilities. 
(ii) A necessary change need be brought in the orientation of medical education as distinct from the efforts made hither to at reorienting medical curriculum. There is a need to include strong social science components in medical education such that the medical professionals can comprehend the complex social, economic, and political context in which medicine operates. Secondly, the clinicians should, as a matter of routine, be pulled out from their ivory towers to engage in preventive care/get involved in strengthening preventive and promotive services.

\section{Conclusion}

With respect to the challenges facing public hospitals in India, it need be remembered that the sorry state of affairs of public healthcare in the country is not for want of policies or managerial skills or for want of latest technologies. The situation is what it is because it suits the interests of the dominant classes in the society. To undo this conundrum ought to be much more than a bureaucratic or technocratic putsch. This is a situation which demands popular based mobilization of the widest possible sections of the society, especially the working masses to support policy initiatives directed at demolishing the elite capture of healthcare and medical profession in the country.

From a hospital administrator's point of view, our account would indeed be very disappointing as there are no readymade shortcuts on the offer to improve the outcomes. Nonetheless, it is important to realize that health is a social phenomenon and a public hospital is a social institution which cannot be studied in isolation from the societal conditions in which it operates. The analysis presented here is in conformity with this reality. However, we are sure that there still are public hospitals that offer much to learn in terms of internal workings of these hospitals for improving the services of a public hospital.

Taken overall, the public healthcare system in the country stands at crossroads where there is little in the present system that is worth emulating. However, even as the adversities seem insurmountable, the solution lies in propagating and creating space for an alternative paradigm both in the realm of theory and practice. In order that theory gains in virility, it must develop the language to articulate people's struggles for an alternative development paradigm.

\section{Conflict of Interests}

The authors declare that there is no conflict of interests regarding the publication of this paper.

\section{References}

[1] Government of India (GOI), Health Survey and Development Committee, vol. 2, Government of India Press, 1946.

[2] Government of India (GIO), Rural Health Statistics 2012, Ministry of Health and Family Welfare, New Delhi, India, 2013.
[3] "Health Nutrition and Population Statistics," World Development Indicators, World Bank Data Bank, http://databank.worldbank.org/data/views/variableselection/selectvariables.aspx ? source=health-nutrition-and-population-statistics.

[4] Government of India (GOI), District Level Household and Facility Survey 2007-08, Ministry of Health and Family Welfare, 2010.

[5] S. Ghosh, "Catastrophic Payments and Impoverishment Due to Out-of-Pocket Health Spending: The Effects of Recent Health Sector Reforms in India," Asia Health Policy Program Working Paper 15, 2010, Working paper series on health and demographic change in the Asia-Pacific, Stanford University Walter H. Shorenstein Asia-Pacific Research Center Asia Health Policy Program.

[6] Government of India (GOI), Morbidity, Healthcare and the Condition of the Aged, NSSO, Ministry of Statistics and Programme Implementation, 2006.

[7] (RHS), Rural Health Statistics in India 2011, Statistics Division, Ministry of Health and Family Welfare, New Delhi, India, 2011.

[8] R. Mehta, B. Gulshan, A. P. Singh, and M. Khejriwal, "A Peek into the Future of Healthcare: Trends for 2010, Technopak perspective: A quarterly report," Quoted in 'High Level Expert Group Report on Universal Health Coverage for India, Instituted by Planning Commission of India, 2010.

[9] American Medical Association (AMA), "International Medical Graduates in American Medicine: Contemporary challenges and opportunities," A position paper by the AMA-IMG Section Governing Council, 2010, http://www.ama-assn.org/resources/ doc/img/international-medical-graduates-in-american-medicine.pdf.

[10] Center for Enquiry into Health and Allied Topics (CEHAT), "Changing Health Budgets," Centre for Enquiry into Health and Allied Themes, Research Centre of Anusandhan Trust, 2006.

[11] CBHI, “Table 1. 1. 3, National Health Profile, 2005," Ministry of Health and Family Welfare, Government of India, New Delhi, India, CBHI (Central Bureau of Health Intelligence), 2005, http://cbhidghs.nic.in/CBHI\%20Book/chapterl.pdf.

[12] GOI, Table 6. 2. 2 State/UT Wise Number of Govt. Hospitals and Beds in Rural and Urban Areas (including CHCs) in India (Provisional), in "Health infrastructure" in "National Health Profile, 2011', Central Bureau of Health Intelligence, Ministry of Health and Family Welfare, 2011.

[13] "National Health Accounts 2004-05 (With Provisional Estimates from 2005-06 to 2008-09)," GOI 2004-05, National Health Accounts Cell, Ministry of Health and Family Welfare, New Delhi, India.

[14] T. Dunning, "Structural Reform and Medical Commerce: The Political Economy of Cuban Health Care in the Special Period," Department of Political Science, University of California, Berkeley, Paper was prepared for delivery at the 2001 meeting of the Latin American Studies Association, Washington, DC, USA, 2001, http://lasa.international.pitt.edu/Lasa2001/ DunningThad.pdf.

[15] RBI: Reserve Bank of India, Handbook of Statistics on Indian Economy, 2013, http://rbidocs.rbi.org.in/rdocs/Publications/ PDFs/FHB160913FLS.pdf.

[16] D. Nandan, K. S. Nair, and U. Datta, "Human resources for public health in India: issues and challenges," Health and Population: Perspectives and Issues, vol. 30, no. 4, pp. 230-242, 2007. 
[17] M. Rao, K. D. Rao, A. S. Kumar, M. Chatterjee, and T. Sundararaman, "Human resources for health in India," The Lancet, vol. 377, no. 9765, pp. 587-598, 2011.

[18] High Level Expert Group (HLEG), "Human resources for health," in High Level Expert Group Report on Universal Health Coverage for India, Planning Commission, Government of India, 2011.

[19] K. Rao, A. Bhatnagar, and P. Berman, "India's health workforce: size, composition and distribution," in World Bank/Public Health Foundation of India, J. La Forgia and K. Rao, Eds., India Health Beat, New Delhi, India, 2009.

[20] World Health Organization (WHO), Global Atlas of the Health, Workforce, Geneva, Switzerland, 2010.

[21] M. D. John, S. J. Chander, and N. Devadasan, "National Urban Health Mission: An analysis of strategies and mechanisms for improving services for urban poor," Background paper for National Workshop on Urban Health and Poverty, 2-3 July 2008, New Delhi, organized by Ministry of Housing and Urban Poverty Alleviation, Government of India, 2008, http://www .academia.edu/855928/National_Urban_Health_Mission_An_ analysis_of_strategies_and_mechanisms_for_improving_services_for_urban_poor.

[22] K. Muralidharan, N. Chaudhury, and J. Hammer, "Is There a Doctor in the House? Medical Worker Absence in India," Working paper, Department of Economics, Faculty of Arts and Sciences, Harvard University, 2011, http://scholar.harvard.edu/ files/kremer/files/is_there_a_doctor_in_the_house_-_12_april_ 2011.pdf.

[23] American Medical Association, "International medical graduates in American medicine: Contemporary challenges and opportunities," A position paper by the AMA-IMG Section Governing Council, AMA Press, Chicago, Ill, USA, 2012, http://nycsprep.com/pdf/international-medical-graduates.pdf.

[24] N. Bhola, R. Kumari, and T. Nidha, "Utilization of the health care delivery system in a district of North India," East African Journal of Public Health, vol. 5, no. 3, pp. 147-153, 2008.

[25] Government of Uttrakhand, "Department of Information and Public Relations," Press Note, 2011, http://www.cm.uk.gov.in/ upload/pressrelease/Pressrelease-280.pdf.

[26] N. Chandra, "Delhi hospital pays high price for excellence," India today, 2012, http://indiatoday.intoday.in/story/delhi-hospital-pays-high-price-for-excellence/1/200025.html.

[27] Jan Swasthya Abhiyan, Globalization and Health, 2006.

[28] D. N. Jha, "All India Institute of Medical Sciences faces exodus of top doctors," Times of India, 2012, http://articles.timesofindia .indiatimes.com/2012-05-03/delhi/31555155_1_faculty-association-voluntary-retirement-faculty-members.

[29] B. S. Perappadan, "Private hospitals advertise at AIIMS to recruit doctors," The Hindu, 2012, http://www.thehindu.com/ todays-paper/tp-national/private-hospitals-advertise-at-aiims -to-recruit-doctors/article3389387.ece.

[30] India, National Health Accounts 2004-05 (with Provisional Estimates from 2005-06 to 2008-09), Ministry of Health and Family Welfare, New Delhi, India, 2004-05.

[31] T. B. MacCulay, "Minute on Indian Education," The British Parliament, 1835, http://www.columbia.edu/itc/mealac/pritchett/ 00generallinks/macaulay/txt_minute_education_1835.html.
[32] S. Manmohan, "Of Oxford, economics, empire, and freedom," The Hindu, 2005, http://www.hindu.com/2005/07/10/stories/ 2005071002301000.htm.

[33] D. K. Das and A. Verma, "The armed police in the British colonial tradition: the Indian perspective," Policing, vol. 21, no. 2, pp. 354-367, 1998.

[34] Asian Centre for Human Rights, Torture in India, 2011, Asian Centre for Human Rights, 2011.

[35] R. Blackely, "Ghulam Nabi Azad says late night TV will help slow India's birth rate," The Sunday Times, 2009.

[36] V. W. Sidel and R. Sidel, Serve the People: Observations on Medicine in the People's Republic of China, Becon Press, Boston, Mass, USA, 1973.

[37] R. Sidel and V. W. Sidel, The Health of China, Zed Press, London, UK, 1982.

[38] Sokhey Committee, Sub-Committee on National Health, National Planning Committee, Vora and Co Publishers, Bombay, India, 1948.

[39] Mudaliar Committee, Health Survey and Development Committee, Government of India, New Delhi, India, 1959.

[40] D. Banerji, Health and Family Planning Services in India: An Epidemiological, Sociocultural and Political Analysis and a Perspective, Lok Paksh, New Delhi, India, 1985.

[41] D. Banerji, "Evolution of health services in India," in In Search of Diagnosis: Analysis of Present System of Health Care, A. J. Patel, Ed., 1977, Published by Voluntary Health Association of India for Medico Friend Circle.

[42] D. Banerji, "Objectives of medical education," in In Search of Diagnosis: Analysis of Present System of Health Care, A. J. Patel, Ed., Medico Friend Circle, New Delhi, India, 1977.

[43] M. Kaushik, A. Jaiswal, N. Shah, and A. Mahal, "High-end physician migration from India," Bulletin of the World Health Organization, vol. 86, no. 1, pp. 40-45, 2008.

[44] K. Yadav, P. Jarhyan, V. Gupta, and C. Pandav, "Revitalizing rural health care delivery: can rural health practitioners be the answer?" Indian Journal of Community Medicine, vol. 34, no. 1, pp. 3-5, 2009.

[45] C. Sathyamala, O. Mittal, R. Dasgupta, and R. Priya, "Polio eradication initiative in India: deconstructing the GPEI," International Journal of Health Services, vol. 35, no. 2, pp. 361-383, 2005.

[46] Jan Swasthya Abhiyan, New Technologies in Public Health: Who Pays and Who Benefits? 1st edition, 2007.

[47] R. Dasgupta and I. Ghanashyam, "Connecting the DOTS: spectre of a public health iatrogenesis?" Indian Journal of Community Medicine, vol. 37, no. 1, pp. 13-15, 2012.

[48] A. K. Maurya, A. K. Singh, M. Kumar et al., "Changing patterns and trends of multidrug-resistant tuberculosis at referral centre in Northern India: a 4-year experience," Indian Journal of Medical Microbiology, vol. 31, no. 1, pp. 40-46, 2013.

[49] E. Hong, Globalisation and the Impact on Health: A Third World View, The Peoples' Health Assembly, Savar, Bangladesh, 2000.

[50] M. Gandy, "Deadly alliances: death, disease, and the global politics of public health," PLoS Medicine, vol. 2, no. 1, pp. e4.9e4.11, 2005.

[51] R. Baru, A. Acharya, S. Acharya, A. K. Shiva Kumar, and K. Nagaraj, "Inequities in access to health services in India: caste, 
class and region," Economic and Political Weekly, vol. 45, no. 38, pp. 49-58, 2010.

[52] R. Duggal, "Health Care and New Economic Policies, the Further Consolidation of the Private Sector in India," Paper Presented at the National Seminar on the Rights to Development, University of Mumbai, Mumbai, India, 1998.

[53] Jan Swasthya Abhiyan, "Health System in India: Crisis and Alternatives," Towards the National Health Assembly II, Booklet 2, 2006.

[54] S. Bhide and R. Shand, "Inequalities in income growth in india before and after reforms," South Asia Economic Journal, vol. 1, no. 1, pp. 19-51, 2000.

[55] A. Marriot, "Blind Optimism Challenging the myths about private health care in poor countries," Oxfam Briefing Paper 125, 2009.

[56] L. V. Gangolli, R. Duggal, and A. Shukla, Review of Healthcare in india, Centre for Enquiry into Health and Allied Themes, Research Centre of Anusandhan Trust, 2005.

[57] Arti Dhar, "Activists up in arms against new proposal on health care," The Hindu, 2012.

[58] V. Bajpai and A. Saraya, "User charges as a feature of health policy in India: a perspective," National Medical Journal of India, vol. 23, no. 3, pp. 163-170, 2010.

[59] L. M. Franco, S. Bennett, and R. Kanfer, "Health sector reform and public sector health worker motivation: a conceptual framework," Social Science and Medicine, vol. 54, no. 8, pp. 12551266, 2002.

[60] M. Chaudhary, "Public spending on health in low-income states and central transfers," Financing Human Development, Policy Brief 1, National Institute of Public Finance and Policy, 2006.

[61] WHO, Primary Health Care: Report of the International Conference on Primary Health Care, Alma-Ata, USSR, Geneva, Switzerland, 1978.

[62] J. Y. Kim, "World Bank Group President Jim Yong Kim’s Speech at World Health Assembly: Poverty, Health and the Human Future," The World Bank, 2013, http://www.worldbank.org/en/ news/speech/2013/05/21/world-bank-group-president-jim-yongkim-speech-at-world-health-assembly.

[63] K. Srinath Reddy, "Universal Health Coverage in India: the time has come," National Medical Journal of India, vol. 25, no. 2, pp. 65-67, 2012.

[64] Arti Dhar, "Panel on health coverage addresses World Bank concerns," The Hindu, 2011.

[65] S. Makkar, "Universal healthcare plan may be nixed," The Wall Street Journal, 2012, http://www.livemint.com/.

[66] E. R. B. Cruz and R. S. S. Perea, "National training program for comprehensive community physicians, Venezuela," MEDICC Review, vol. 10, no. 4, pp. 35-42, 2008.

[67] Express News Service, "New MP varsity to teach medicine, engg in Hindi," The Indian Express, 2013, http://www.indianexpress .com/news/new-mp-varsity-to-teach-medicine-engg-in-hindi/ $1126170 /$. 


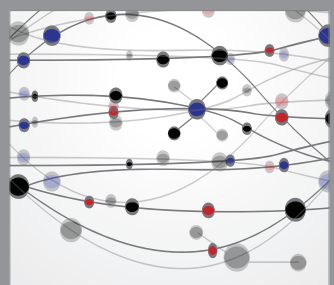

The Scientific World Journal
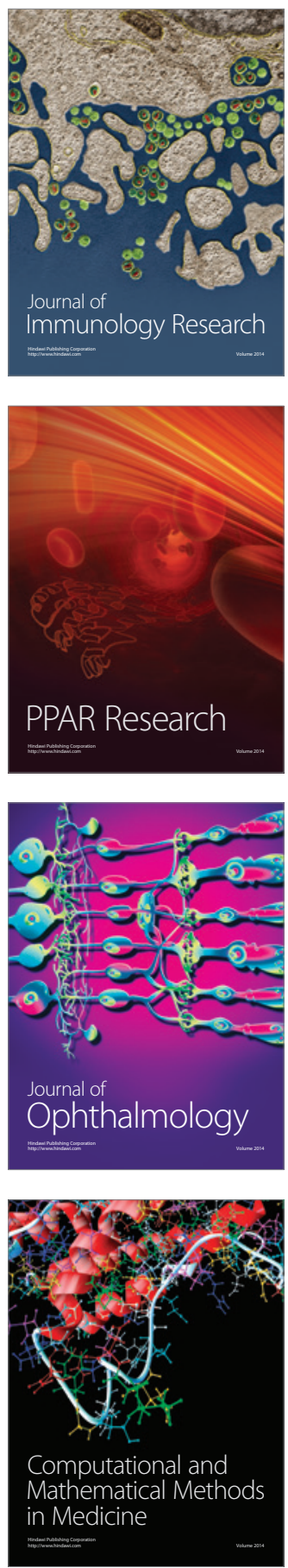

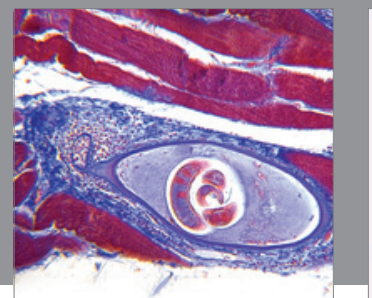

Gastroenterology

Research and Practice
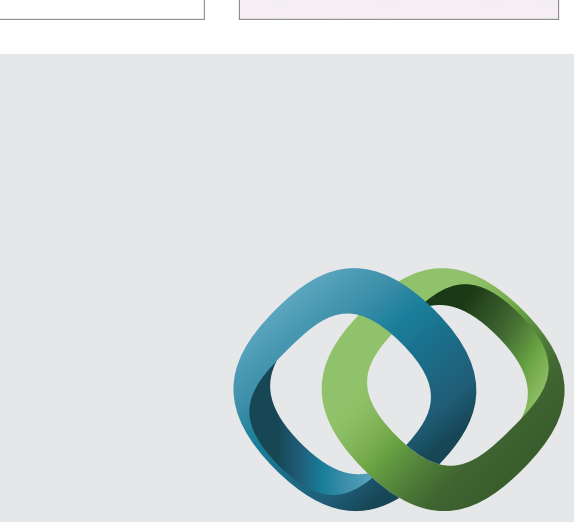

\section{Hindawi}

Submit your manuscripts at

http://www.hindawi.com
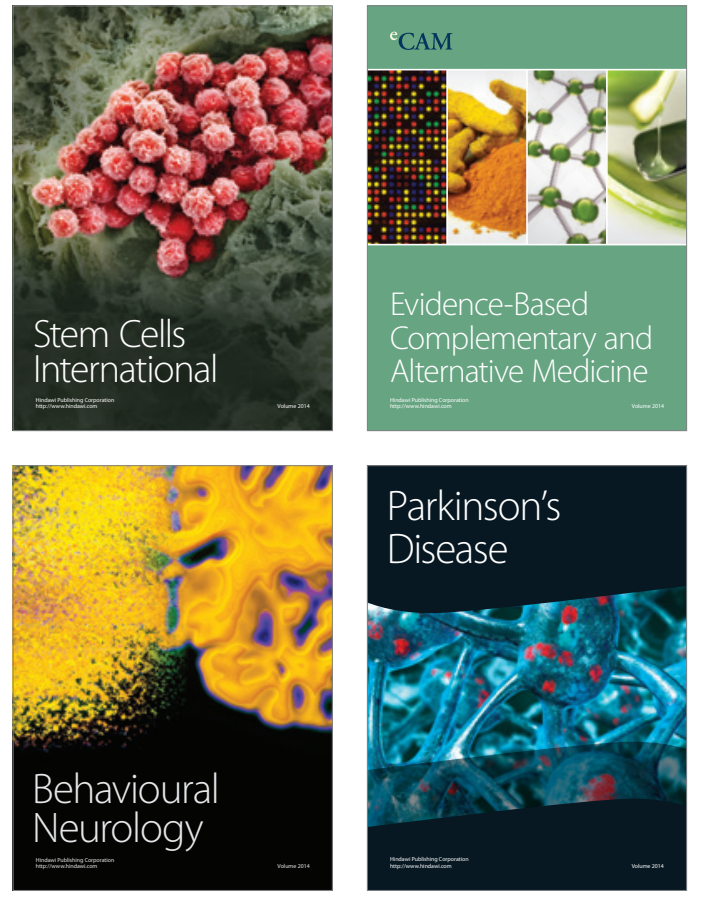
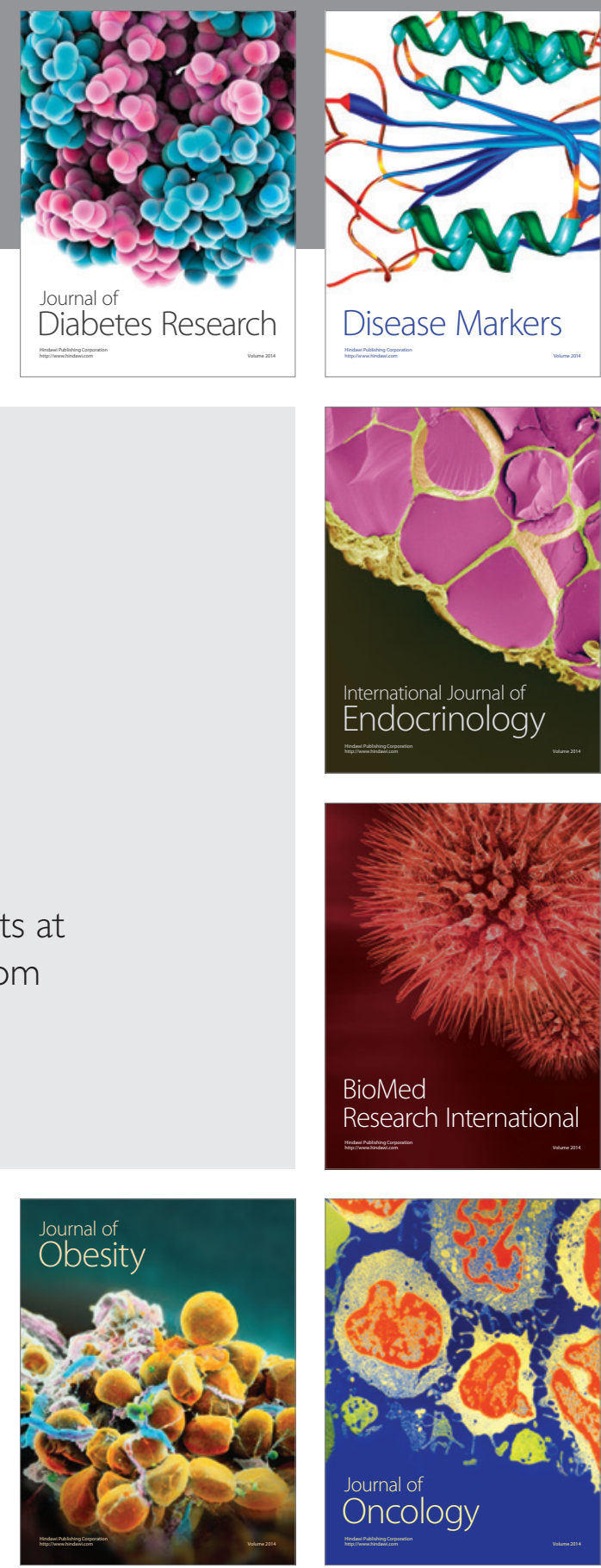

Disease Markers
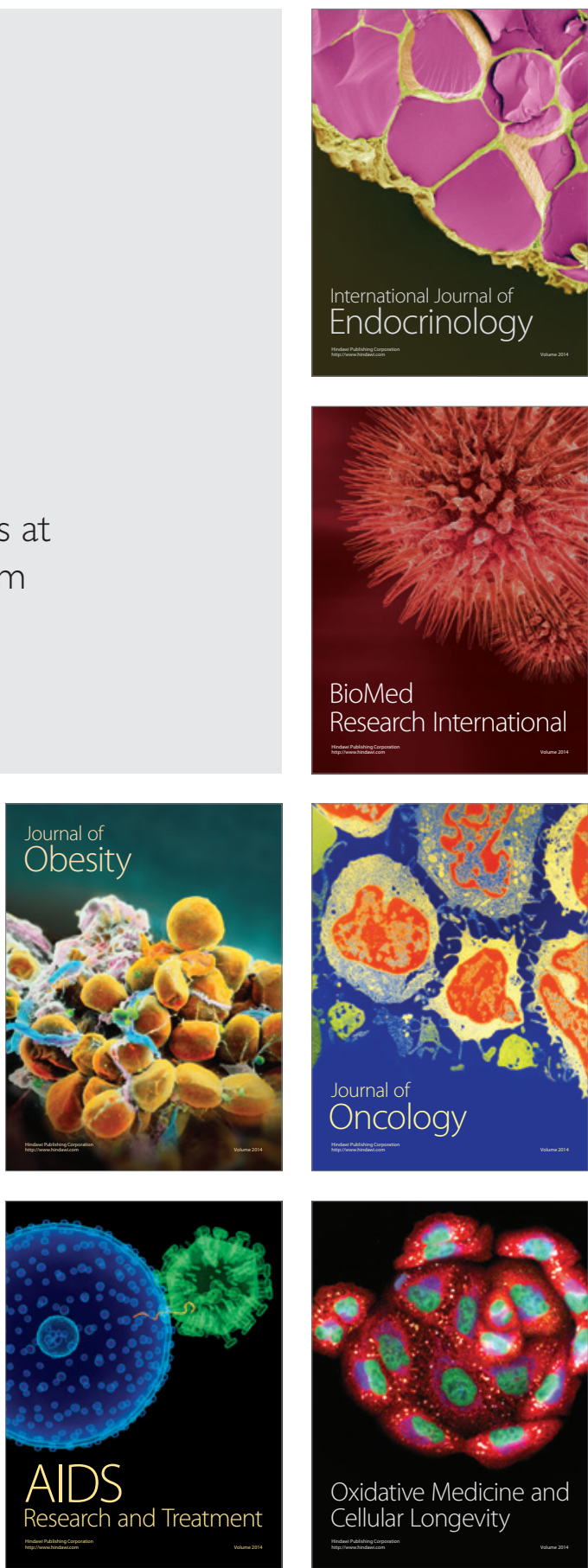